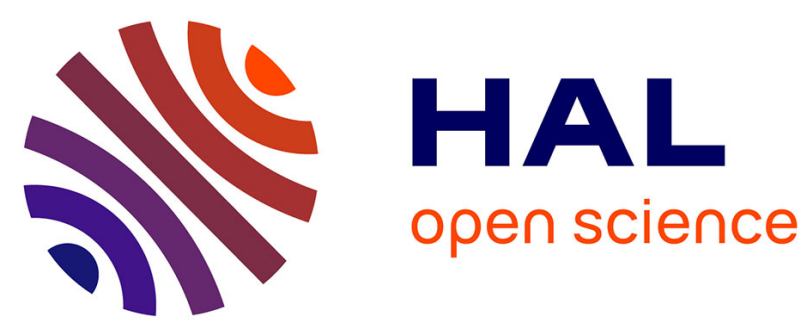

\title{
Cost and Quality of Service Analysis of Production Systems Based on the Cumulative Downtime
}

\author{
Jose Antonio Faria, Eusebio Manuel Nunes, Manuel Antonio Matos
}

\section{To cite this version:}

Jose Antonio Faria, Eusebio Manuel Nunes, Manuel Antonio Matos. Cost and Quality of Service Analysis of Production Systems Based on the Cumulative Downtime. International Journal of Production Research, 2009, 48 (06), pp.1653-1684. 10.1080/00207540802068631 . hal-00548942

\section{HAL Id: hal-00548942 \\ https://hal.science/hal-00548942}

Submitted on 21 Dec 2010

HAL is a multi-disciplinary open access archive for the deposit and dissemination of scientific research documents, whether they are published or not. The documents may come from teaching and research institutions in France or abroad, or from public or private research centers.
L'archive ouverte pluridisciplinaire HAL, est destinée au dépôt et à la diffusion de documents scientifiques de niveau recherche, publiés ou non, émanant des établissements d'enseignement et de recherche français ou étrangers, des laboratoires publics ou privés. 


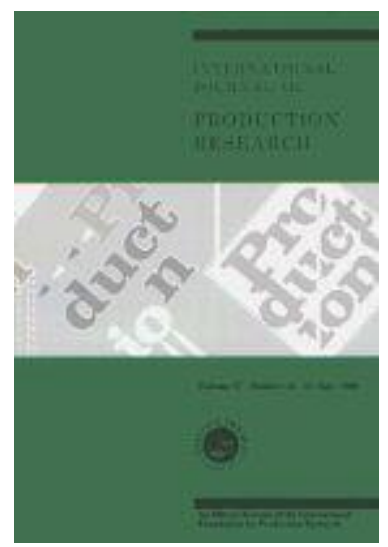

Cost and Quality of Service Analysis of Production Systems Based on the Cumulative Downtime

\begin{tabular}{|r|l|}
\hline Journal: & International Journal of Production Research \\
\hline Manuscript ID: & TPRS-2007-IJPR-0412.R2 \\
\hline Manuscript Type: & Original Manuscript \\
\hline Date Submitted by the \\
Author: & 09-Mar-2008 \\
\hline Keywords: List of Authors: & $\begin{array}{l}\text { Faria, Jose; University of Porto, Faculty of Engineering } \\
\text { Nunes, Eusebio; School of Engineering, University of Minho, } \\
\text { Department of Production Systems } \\
\text { Matos, Manuel; Inesc Porto }\end{array}$ \\
\hline OPERATIONS MANAGEMENT, DESIGN OF PRODUCTION SYSTEMS, \\
Reywords (user): & $\begin{array}{l}\text { Production systems Analysis and Design , Cost and Quality of } \\
\text { Service }\end{array}$ \\
\hline \multicolumn{2}{|l}{} \\
\hline
\end{tabular}

\section{S) ScholarONE" \\ Manuscript Central}




\title{
Cost and Quality of Service Analysis of Production Systems Based on the Cumulative Downtime
}

\author{
José Faria $^{1,2}$, Eusébio Nunes ${ }^{3}$, Manuel Matos ${ }^{1,4}$ \\ ${ }^{I}$ Faculty of Engineering, University of Porto \\ ${ }^{l}$ Institute for Systems and Robotics \\ ${ }^{3}$ School of Engineering, University of Minho \\ ${ }^{4}$ INESC Porto, Rua Roberto Frias
}

Correspondence to:

Prof. Jose A. Faria

Institute for Systems and Robotics

Faculty of Engineering, University of Porto

Rua Roberto Frias, $\mathrm{s} / \mathrm{n}$

4200-465 Porto, Portugal

phone: +351.22 .508 .1831$

fax: +351.22 .508 .1443$

email: jfaria@fe.up.pt 


\section{Abstract:}

The paper presents a method for the analysis and design of industrial production systems based on a joint assessment of the cost and the quality of service. The operation of a production system is seen as the accomplishment of a sequence of missions, each one corresponding to the cost-effective production and delivery of a specified quantity of products within a specified time frame. The paper shows that the probability of successfully accomplishing a mission is a non linear function of the cumulative production downtime and that this time can not be obtained using conventional Markov based techniques. The paper also introduces an analytical model and a procedure that allows the density function of the downtime to be obtained and shows how, using these tools, the production costs and the quality of service may be assessed and related to the internal design of the shop floor. The method seems to be particularly valuable in the analysis of production systems integrated in just-in-time supply chains, in which the reliability of the deliveries is an outstanding requirement.

Keywords: Production systems, Quality of service, Deliveries Reliability, Cost, Analysis, Design

\section{Introduction}

For a production system integrated in a supply chain, the fundamental mission may be defined as the cost-effective production and delivery of parts and goods within the specified time frames. According to this, business contracts between the buyer (the retailer or manufacturer) and the seller (the supplier) often specify the expected service level and define penalties that will be applied to the suppliers if they do not respect the delivery plans. These penalties may be assigned to each single delivery failure, or to the cumulated failures during a given period, e.g., a year. Even when the business contracts do not include such "hard" penalties clauses, industrialists always look very carefully at the reliability of the deliveries because it has a direct impact upon client satisfaction and a low reliability will certainly undermine their reputation.

This is particularly true for the just-in-time supply chains, in which the inventory level at the logistical nodes is low and the materials coming from the suppliers go directly to the assembly lines of the finished products. In these conditions, a single failure has the potential to cause the entire network to fail (Rice, 2003) and, in multi-tier supply chains, it is likely that the effects of a failure are amplified as it propagates from tier to tier (Lee 1997). The mechanisms by which disturbances are transmitted along a supply chain and 
cause a variety of problems such as long lead-times, inability to meet customer demand and increases in costs are examined in Riddalls (2002) and Qi (2005). Ludema (2006) and Wiendahl (2003) analyse the interdependencies across supply chain partners, and $\mathrm{Wu}$ (2007) presents a method for modelling the propagation of the failures and understanding the behaviour of the supply chains under unexpected changes on the normal flow of materials.

With this in mind, it is clear that just-in-time suppliers should have very high performance standards in order to be competitive. The Supply Chain Operations Reference-model (SCOR 1996) defines two main dimensions for the assessment of a supplier: customer-facing performance, where reliability, responsiveness and flexibility are measured, and internal-facing performance, where cost and assets are measured. This paper will mainly focus upon two of these attributes: the reliability of the deliveries and the production cost both of which are critical in the context of just-intime supply chains.

The reliability of the deliveries can always be improved through the increase of safety stock buffers, the reinforcement of maintenance resources, or the redundancy of critical manufacturing equipment. However, as remarked in Das (2007), any attempt to improve reliability will also have a detrimental effect increasing the production cost. Thus being, in order to be effective, analysis strategies should consider, on one end, the reliability of the individual pieces of equipment and the layout of the production system and, on the opposite end, the key factors of competitiveness, namely the quality of the service and the global production costs. For a large production system, containing several manufacturing cells, with heterogeneous equipment and multiple wip buffers, this kind of analysis will certainly be a complex task.

Despite the vast amount of technical and scientific research devoted to the analysis and design of production systems, the development of a comprehensive framework allowing the technical design at the shop floor level and the performance at the business level to be related remains a largely open and challenging research issue. In fact, as the literature review provided in Section 2 will highlight, there is a gap between the research work addressing the analysis and assessment of the production systems from a business and management perspective, and the research addressing the technical design and operation 
at the shop floor level, e.g., lot and inventory sizing, layout design, maintenance and production scheduling.

These claims have led us to the investigation presented in the paper. Its final goal is the development of an integrated approach for the analysis and design of cost-effective production systems that should carry out just-in-time deliveries. The approach is based on a mission oriented view of the production systems, meaning that their operation is seen as a sequence of missions, each one corresponding to the production and delivery of a given quantity of products within a given time frame.

A typical production system may contain several cells, each one with several pieces of equipment submitted to random failure processes. The effects of the failures within the production system will reflect the flow of materials and they depend on the wip and finished product buffers that may exist between the initial points of failure and the output (figure 1). In order to model the dynamics of the failures and assess their impact upon the deliveries, two main concepts will be employed: the production system canonical model and the cumulated downtime at the output. The canonical model summarizes the behaviour of the system from the point of view of its downstream consumers. It defines a global failure rate and an equivalent reposition process for the entire production system and so it is particularly useful for the assessment of the reliability of the deliveries. The canonical model of a particular system depends on multiple factors, namely, the layout, the equipment failure rates, the maintenance policies and the inventory sizing. Even so, it may be obtained through a systematic procedure, which has already been introduced in a previous paper (Faria 2006).

[ Figure 1 - Failure propagation ]

The need to consider the cumulated downtime emerges from the fact that a single machine breakdown is not likely to cause, per se a failure at the output. Instead, a mission (or delivery) failure will occur if the cumulated production breakdowns during the time frame of that mission exceed the existing inventory. The cumulated downtime is the combination of two other random variables - the number and the duration of the failures - whose distributions are both obtained from the canonical model. Using the analytical tools based on the concepts that will be presented in the paper, system 
managers will then be able to evaluate, for different design scenarios (i) the probability of successful accomplishment of the deliveries, (i) the expected service level and (iii) the additional costs due to the failure penalties, and, finally, to choose the design that guarantees the required quality of service at minimum cost. The entire analysis and design process is sketched in figure 2.

[ Figure 2 - Analysis and design process overview ]

The paper is organized in 3 main parts, the first of which is organized in 3 Sections and contains introductory material. Section 2 presents a literature review on analysis and design of industrial production systems and supply chains, and Section 3 presents the production system that will be employed as a real world application for the concepts and tools introduced in the paper. The second part of the paper presents the theoretical foundations of the new approach. Section 4 and 5 present the two business oriented models that will be considered, one pertaining to the production costs, the other to the quality of service. Section 6 presents the reliability model, from which the canonical model and the cumulated downtime distribution are obtained. The third part of the paper contains two Sections. Section 7 provides a detailed numerical application regarding the production system introduced before. Firstly, the system will be designed in order to minimize the global production costs when the following four components are considered: failure penalties, loss of "sales opportunity", extra working time, and safety stocks. In a second case, the design of the system will seek the guarantee of the specified quality of service level. Special attention will be given to the finished product buffer, because its design is subjected to conflicting requirements and because using buffers to handle machine breakdowns is a well established practice in manufacturing. Section 8 presents a number of concluding remarks and perspectives for future work. Finally, two annexes containing complementary material concerning the numerical example will be included: annex 1 presents a summary of the relevant formulae, whereas Annex 2 contains the quantitative input data for the reliability analysis.

\section{Literature review}

There is vast amount of technical and scientific work devoted to the analysis, assessment and design of production systems developed by several research 
communities, from industrial engineering to operations research and management. Many of that research addresses the production systems from a management perspective and tries to understand the applicability and effectiveness of industrial practices and systems and develop the knowledge managers need to choose the solutions that better fit the needs of their organisations, as in Ahmad 2004. As another example, Chenall (1996) presents an empirical investigation that tries to establish links between organisational performance (expressed in terms of attributes such as delivery speed, scrap, rework and labour efficiency), and industrial management and engineering practices (namely technology policy, planning framework and product design infrastructure). Often, this line of research focuses on financial related issues (e.g., Murphy (1990), Pandya (1995) and Boyd (2002)). Buzacott (2004) shows the importance of joint consideration of asset-based financing and operational production decisions and Fullerton (2003) presents an empirical study that investigates whether the systematic implementation of just-in-time methods and practices affects the financial performance of the firms.

In Maksoud (2005), non-financial performance measurements in manufacturing companies are analysed. This research often involves empirical studies addressing a particular region, e.g., White (1999) presents a survey regarding the effectiveness of just in time techniques in USA companies, Reiner (2006) presents an empirical benchmarking study of 65 European and North American companies in which supply chain efficiency and financial performance are compared and Shrivastava (2006) examines the linkages between factors affecting total quality management and organisational performance in Indian industry. Other studies are oriented to a particular industrial sector, e.g., Schmitz (2004) contrasts intra and inter-organisational performance measurement concepts within a supply chain in the automotive industry, and Chiang (2007) presents a model for the semi-conductor industry. These studies provide an overall understanding of the competitiveness drivers and allow the success and potential of management decision strategies to be assessed. Therefore, they facilitate the re-engineering of business processes and systems, as in Van Hoek (1998) and Kuwaiti (2000). Also, Chan (2003) proposes a framework for performance assessment, based on three quantitative measurements (cost, resource utilization and quality) and four qualitative measurements (flexibility, visibility, trust and innovativeness), and a decision-making technique for solving the multi-criteria problems - the analytical hierarchy process tool developed by Saaty (1999). 
However, these studies often stay at a global level and so provide little insight on the physical design of the shop floor that actually drives performance. This may undermine their interest when low level design decisions, e.g., the layout of the production system or the redundancy of the manufacturing equipment, have to be made. As noted by Beamon (1999), performance measurement systems in the context of just-in-time supply chains are biased towards financial metrics, lack system thinking and miss the supply chain context, e.g., Gunasekaran (2001) and Holmberg (2000).

In contrast, another class of papers is oriented towards low-level shop-floor analysis and optimization. Typical questions addressed here regard lot and inventory sizing, layout design, and production and maintenance scheduling. For example, Berg (1994) presents a method for the computation of a number of shop-floor metrics, namely the servicelevel to customers expected, the inventory stocked, the machines and repairmen utilization, and the shutdown policies. The optimization of the preventive maintenance strategies is addressed in a large number of papers that have appeared during the recent years based on joint production and maintenance models and reliability theory, e.g., Rolstandas (1995), Yucesan (2000), Hong (2003), Ajodhya (2004) and Chelbi (2004). In Gupta (1998), an algorithm to integrate the preventive maintenance actions in a pullflow just-in-time production system is presented. Another topic that receives a significant attention from the research community is the design of buffers as a mean to attenuate the disruptions caused by unreliable machines. For example, Enginarlar (2002) presents a method for selecting buffering in serial lines containing identical machines with exponential distributions and, in Meerkov 2006, the method is extended to Bernoulli machines. A comprehensive review of the techniques for buffer design using dynamic programming and heuristic based models may be found in Huang (2002).

These articles frequently deal with systems that work under somewhat idealized operating conditions and the models proposed often adopt restrictive assumptions that limit their application scope. Typical assumptions include the exponential distribution of the stochastic processes, the linearity of the cost models, and a constant demand rate. For example, Kyriakidis (2006) deals with a simple system subject to a deterioration that supplies raw material to a subsequent production unit, acting as a "pull" system with a constant demand. Similarly, Giordano (2002) considers the optimization of the 
safety stock for a single-part type, single-unreliable machine production system; Van Ryzin (1993) investigates optimal production control for a tandem of two machines; and Moinzadeh (1997) analyzes an unreliable bottleneck, assuming constant production and demand rate, constant restoration time and exponential failure processes. Other authors assume less restrictive conditions but, on the other hand, they focus on specific classes of problems. This is the case, for example, of Mahadevan (1993), where a combined buffer leveling and material handling devices analysis is presented, Shiau (2003), where an analysis is presented regarding the optimal allocation of inspection resources for manufacturing products with multiple quality attributes and Hsieh (2007), where the performance of an automated wip storage system consisting of a conveyor and a rotary rack is analysed.

A final point that should be remarked here is the fact that, although machine reliability is widely recognized as an important factor for the global performance of the production systems, relatively few system level analysis methodologies are able to integrate the reliability of the manufacturing equipment in their models, as noted in (Das 2007). Instead, it is often assumed that the machines are available at all times. Similarly, at the supply chain level, there has been relatively little work reported on system-wide delivery failures analysis. As remarked in Jüttner (2003), the concepts of supply chain vulnerability and supply chain risk are still in their infancy.

\section{The PartsSupplier production system}

This Section introduces the PartsSupplier production system that will be considered throughout the paper as a practical application example. This system has to deliver, at the end of every working day, a specified quantity of parts to an original equipment manufacturer (OEM) plant, where they are assembled into a final product. The structural and operational aspects of PartsSupplier production system will be presented in the next two paragraphs. The name of the company was changed and some facts regarding the production system were simplified for clarity, but without compromising its significance as a practical, real world, example of a mass production company in the automotive industry that supplies an OEM plant. 
The business contract with the OEM specifies two types of penalties that will be applied to the PartsSupplier company when it does not execute the scheduled deliveries in time. A first penalty type is assigned on a delivery basis: each time a delivery does not respect the due quantity, a fixed penalty will be applied to the supplier. A second penalty type concerns the quality of the service level on a yearly basis. In this case, a penalty will be applied if the supplier does not respect a minimum service level specified in terms of the maximum number of delivery failures per year or in terms of the cumulated quantity that was not delivered in time. Thus being, the optimal design of the system would be the one that assures the compliance with the agreed service level at minimum cost. In regards to the production costs, besides the failure penalties, two other cost components directly related to the reliability of the deliveries should be taken into account: the safety stock and the sales opportunity loss, corresponding to the products that were not sold due to a delivery failure.

\subsection{System structure}

The layout of the PartsSupplier production system is sketched in figure 3. It contains a main assembly line and three manufacturing cells. For the sake of simplicity, cell $_{1}$ and $\mathrm{cell}_{2}$ are assumed to be identical and have $\mathrm{n}$ identical machines. On the contrary, cell $_{3}$ contains two types of machines: those repaired in-house and those demanding external maintenance resources (spare parts or skilled technicians). As these machines present a much longer "time-to-repair", there is a wip buffer at the output of this cell in order to prevent its internal failures from propagating to the assembly line. The assembly line also contains some critical equipment the maintenance of which demands external resources. In this case, system managers considered that it would not be cost effective to maintain a safety stock and decided to improve the reliability of the assembly line through the installation of additional equipment in passive redundancy (when a machine failure occurs, a reconfiguration procedure is engaged in order to activate a redundant machine). As the failures on the deliveries are likely to cause significant disturbances in the OEM plant, there is a finished product safety stock buffer at the output of the system which is intended to isolate the external deliveries from the breakdowns of the internal machines. 
[ Figure 3 - The PartsSupplier production system ]

\subsection{System operation}

The nominal daily production capacity of the PartsSupplier plant, $P_{N}$, is equivalent to the daily demand, $D_{N}$. Figure 4 shows the evolution of the content of the output buffer in three different situations. In the absence of failures (figure 4.a), a quantity $P$ equivalent to $D_{N}$ will be produced during $T$ (the duration of a working day) and delivered to the client. The stock level at the end of the day, $I^{l}$, will be equal to $S S+D_{N}$, and so no extra work will be needed. Figure 4.b shows a situation in which there is a loss of production (due to the internal breakdowns), which is smaller than the safety stock. As the inventory at the end of the day, $I^{2}$, is greater than $D_{N}$, the scheduled quantity will be delivered to the client, but there will be an extra working time equivalent to the duration of the failures, in order to restore the nominal content of the buffer. Finally, figure 4.c shows a situation where the loss of production is greater than the safety stock meaning that the inventory is not enough to satisfy the demand $\left(I^{3}<\right.$ $D_{N}$ ). In this case, the extra working time will be constant and equal to the time required to produce a quantity of parts equivalent to the safety stock $S S$.

[ Figure $4-$ Evolution of the content of the buffer ]

\section{Production cost analysis}

This Section introduces the analytical tool that is employed in the assessment of the production costs. As explained before, this tool is based on the density function of the cumulated downtime at the output, $f_{T_{D}}(t)$, the determination of which will be covered later, in Section 6. From the previous presentation of the PartsSupplier production system, it becomes apparent that four cost components should be considered in the design of the system: (i) the penalties for the delivery failures, which is a cost proportional to the number of failures that will be denoted as $F_{C}$; (ii) the cost corresponding to the sales opportunity loss, which is proportional to the quantity of products not delivered to the customer and denoted as $S_{C}$; (iii) the cost corresponding to 
the extra working time needed to ensure the replenishment of the safety stock to its nominal level SS, which is proportional to the downtime and denoted as $X_{C}$; (iv) the cost of the safety stock, which is proportional to the size of the buffer and denoted as $B_{C}$. If $T_{D}$ is the total downtime of the production system during a working day, the daily production costs, $P C$, resulting from the sum of these four components are given by:

$$
P C=\left\{\begin{array}{ll}
\alpha_{X} T_{D}+\alpha_{B} T_{S S} & \text { for } T_{D} \leq T_{S S} \\
\alpha_{F}+\alpha_{S}\left(T_{D}-T_{S S}\right)+\alpha_{X} T_{S S}+\alpha_{B} T_{S S} & \text { for } T_{D} \leq T_{S S}
\end{array}\right\}
$$

where:

- $\quad T_{S S}$ is the number of production hours equivalent to the safety stock at the output buffer;

- $\quad \alpha_{F}$ is the fixed penalty per delivery failure;

- $\quad \alpha_{S}$ is the loss of sales profit for a quantity equivalent to one hour of production;

- $\quad \alpha_{X}$ is the hourly cost rate for the extra working time;

- $\quad \alpha_{B}$ is the cost of holding a safety stock equivalent to one hour of production.

Figure 5 shows a graphical representation of these four cost components. For $T_{D} \leq T_{\mathrm{SS}}$, just the extra working time $\left(\alpha_{X} T_{D}\right)$ and the safety stock cost $\left(\alpha_{B} T_{S S}\right)$ should be added to the base production costs. For $T_{D} \geq T_{\mathrm{SS}}$, there will be a delivery failure and so the loss of sales profit $\left(\alpha_{S}\left(T_{D}-T_{S S}\right)\right)$ and the deliver failure penalty $\left(\alpha_{P}\right)$ also have to be considered. In this situation, as the buffer will be empty at the end of the day, the extra time cost will be fixed and equal to $\alpha_{X} T_{S S}$. The sum of these four cost components is referred to as the cost oriented business model of the production system.

[ Figure 5 - Graphical representation of the production costs ]

As this model is evaluated at design time, only the expected values of the cost components can be estimated, i.e.:

$$
\mathrm{E}[\mathrm{PC}]=\mathrm{E}\left[\mathrm{F}_{\mathrm{C}}\right]+\mathrm{E}\left[\mathrm{S}_{\mathrm{C}}\right]+\mathrm{E}\left[\mathrm{X}_{\mathrm{C}}\right]+\mathrm{E}\left[\mathrm{B}_{\mathrm{C}}\right]
$$

The random variable $T_{D}$ will typically present a high variability because it comes from the combination of two random variables: the number of failures occurred during the mission time frame and the duration of each one of those failure. As the cost model is a non linear function of $T_{D}$, the cost components can not be assessed using the asymptotic 
value of $\overline{T_{D}}$. Instead, the density function $f_{T_{D}}(t)$ should be employed in the evaluation of $P C$ in order to "weight" the cost for each value of $T_{D}$ according to its probability, i.e.:

$$
\mathrm{E}[\mathrm{PC}]=\int_{0}^{\infty} \mathrm{f}_{\mathrm{T}_{\mathrm{D}}}(\mathrm{t}) \times \mathrm{PC}\left(\mathrm{T}_{\mathrm{D}}\right) \mathrm{d}_{\mathrm{T}_{\mathrm{D}}}
$$

Figure 6 may clarify this fundamental idea. The two density functions $f_{T_{D}}^{l}(t)$ and $f_{T_{D}}^{2}(t)$ have the same mean $\overline{T_{D}}$. However, the evaluation of the cost from (3) will give very different results for the two functions because of the non-linear nature of the cost model.

\section{[ Figure 6 - Evaluation of non-linear cost models ]}

The determination of $f_{T_{D}}(t)$ is a key point in the evaluation of the cost function but it will be discussed only in Section 6. For now, it will be assumed that $f_{T_{D}}(t)$ is known and so the cost components can be evaluated as follows. The expected cost due to the failures of the deliveries, $E\left[F_{C}\right]$, is given by the product of the probability of failure, i.e. the probability that $T_{D}>S S$, and of the cost incurred per each failure, $\alpha_{F}$, i.e.:

$$
E\left[F_{C}\right]=\alpha_{F} \int_{S S}^{T} f_{T_{D}}(t) d T_{D}
$$

Similarly, the expected value of the cost corresponding to the loss of sales opportunity is given by:

$$
E\left[S_{C}\right]=\alpha_{S} \int_{s s}^{T} f_{T_{D}}(t)\left(T_{D}-S S\right) d T_{D}
$$

For cost accounting purposes, the extra working time is normally considered as a multiple of a standard time unit $u t$, typically one hour. The number of extra work hours, $\mathrm{n}_{\mathrm{XT}}$, will verify:

$$
\mathrm{n}_{\mathrm{XT}} \text { ut }<\mathrm{T}_{\mathrm{D}}<\left(\mathrm{n}_{\mathrm{XT}}+1\right) \text { ut }
$$

Therefore the expression for the expected value of this cost component will be:

$$
E[X T]=\alpha_{X} \sum_{n=1}^{m} \int_{n-1}^{n} n f_{T_{D}}(t) d T_{D}, \quad m=\frac{T}{u t}
$$

with $m$ being the maximum number of extra working hours. The safety stock is the fourth component of cost to be considered in the evaluation of $E[P C]$. Its value is 
known at design time because it is assumed that the content of the buffer is fixed at the beginning of each working day:

$$
\mathrm{E}\left[\mathrm{B}_{\mathrm{C}}\right]=\alpha_{\mathrm{B}} \mathrm{SS}
$$

The practical application of these procedures to the PartsSupplier production system will be presented in paragraph 7.4.

\section{Quality of service analysis}

In this Section, two other business models will be introduced, one pertaining the number of delivery failures per year, and the other the cumulated quantity not delivered, also per year.

\subsection{Maximum number of failures}

Assume that the maximum allowed number of delivery failures per year specified by the OEM client is $N F_{y}^{s p e c}$. To analyze the design of the system in this situation, a new model relating the probability density function $f_{T_{D}}(t)$ to the business level performance should be considered. If $p$ is the probability of failure of a daily delivery, the number of failures per year, $N F_{y}$, is a random variable that follows a binomial distribution, and so the probability of $N F_{y}=n$ will be given by:

$$
\mathrm{P}_{\mathrm{NF}_{\mathrm{y}}}(\mathrm{n})=\left(\begin{array}{c}
\mathrm{nd}_{\mathrm{y}} \\
\mathrm{n}
\end{array}\right) \mathrm{p}^{\mathrm{n}}(1-\mathrm{p})^{\mathrm{nd}_{\mathrm{y}}-\mathrm{n}}
$$

where $n d_{y}$ is the number of working days per year. Probability $p$ depends on the safety stock $S S$ at the output buffer, and on the cumulated downtime of the production system during the mission time frame. If $S S$ is expressed, as before, in terms of the equivalent hours of production, there will be a delivery failure when the cumulated downtime is greater than $S S$, i.e.:

$$
p=P\left(T_{D}>S S\right) \text { with } P\left(T_{D}>S S\right)=\int_{S S}^{T} f_{T_{D}}(t) d t
$$

Therefore, to ensure that for a given statistical confidence level $\phi$ the supplier respects the specified quality of service, the following relationship should be verified: 


$$
\sum_{n=1}^{N F_{y}^{\text {spec }}}\left(\begin{array}{c}
n d_{y} \\
n
\end{array}\right)\left(\int_{S S}^{T} f_{T_{D}}(t) d t\right)^{n}\left(1-\int_{S S}^{T} f_{T_{D}}(t) d t\right)^{n d_{y}-n}>\phi
$$

To determine the minimum stock required to ensure $N F_{y}^{s p e c}$, relation (10) should be tested for increasing values of $S S$ until a value is reached such that the relation becomes true. The practical application of this procedure will be exemplified in paragraph 7.5.

\subsection{Maximum quantity not delivered}

In this third situation, it is considered that the service level agreement between PartsSupplier and the OEM specifies a maximum cumulated quantity of products per year, $Q_{y}^{s p e c}$, that the supplier may not deliver accordingly to what was planned. If $q_{i}$ is the random variable representing the quantity not delivered each day (expressed in terms of the number of equivalent hours of production), with $m q_{i}$ and $\sigma q_{i}$ being its mean and standard deviation, then, according to the central limit theorem, the cumulated annual quantity, $Q_{y}$, will be a random variable presenting a normal distribution and where:

$$
m Q_{y}=n d_{y} m_{i}, \quad \sigma Q_{y}=\sigma q_{i} \sqrt{n d_{y}}
$$

For this distribution, the value of $Q_{y}$ will stay within $\left[m Q_{y}+1.64 \sigma Q_{y}\right]$ for a confidence level $\phi$ of $95 \%$. Therefore, in order to guarantee the specified quality of service, the following relationship must hold true:

$$
\mathrm{Q}_{\mathrm{y}}^{\mathrm{spec}}<\mathrm{nd}_{\mathrm{y}} \mathrm{mq}_{\mathrm{i}}+1.64 \sigma \mathrm{q}_{\mathrm{i}} \sqrt{\mathrm{nd}_{\mathrm{y}}}
$$

The density function of the daily quantity not delivered $f_{q i}(q)$ is given by:

$$
\mathrm{f}_{\mathrm{qi}}(\mathrm{q})= \begin{cases}\delta(0)=\int_{0}^{\mathrm{SS}} \mathrm{f}_{\mathrm{T}_{\mathrm{H}}}(\mathrm{t}) \mathrm{dt} & \text { for } \mathrm{q}=0 \\ (\mathrm{SS}+\mathrm{q}) \mathrm{dq} & \text { for } 0<\mathrm{q}<\mathrm{T}-\mathrm{SS} \\ 0 & \text { for } \mathrm{q} \geq \mathrm{T}-\mathrm{SS}\end{cases}
$$

Therefore, the mean and the standard deviation of the random variable $q_{i}$ may be obtained from:

$$
\mathrm{mq}_{\mathrm{i}}=\int_{0}^{\mathrm{T}-\mathrm{SS}} \mathrm{qf}_{\mathrm{T}_{\mathrm{H}}}(\mathrm{SS}+\mathrm{q}) \mathrm{dq}
$$




$$
\sigma q_{i}=\sqrt{m_{i}^{2} \int_{0}^{S S} f_{T_{H}}(t) d t+\int_{S S}^{T} f_{T_{H}}(q)\left(q-S S-m_{i}\right)^{2} d q}
$$

Now, for each value of $S S$, it is possible to evaluate $m q_{i}$ and $\sigma q_{i}$ from (14) and (15), and then $m Q_{y}$ and $\sigma Q_{y}$, from (11). Finally, the upper limit for $Q_{y}$ may be estimated from (12). As for the previous situation, the practical application of this procedure will be illustrated in Section 7, paragraph 6.

\section{Reliability analysis}

This Section presents the procedure for the determination of $f_{T_{D}}(t)$. Only the theoretical aspects will be discussed here, since the practical application of the procedure will be broached in Section 7. The description of the PartsSupplier system has provided evidence for two important ideas: (i) from the deliveries to the clients' point of view, the behaviour of a production system may be described in terms of a two-state model, in which the system is either producing (up) or halted (down), as illustrated in figure 7; and (ii) the successful accomplishment of a mission depends on the cumulated downtime at the output of the system (due to the failures that occurred within the mission time frame) versus the safety stock level. We call the couplet frequency of arrival to the down state, $\Lambda_{S}^{o}$, and the density function of the reposition process, $f_{\rho_{S}^{o}}(t)$, the canonical model at the output of the production system:

$$
\mathrm{CM}_{\mathrm{S}}^{\mathrm{o}}=\left\{\Lambda_{\mathrm{S}}^{\mathrm{o}}, \mathrm{f}_{\rho_{\mathrm{S}}^{\mathrm{o}}}(\mathrm{t})\right\}
$$

A similar concept can also be employed to represent (i) the internal behaviour of a cell, (ii) the behaviour at the output of a cell and (iii) the behaviour at the output of a buffer. In the first case, the canonical model will show the frequency of failure and the reposition process at the output of a cell, when only the endogenous failure processes of that cell are being considered. In the second situation, the down state of the model represents the situations where the cell halts its operation, due to an endogenous or to an exogenous failure in an upstream cell. In the latter case, the failure state will correspond to the situations where the buffer is empty and unable to supply the downstream cells. To distinguish these three models in a particular manufacturing unit $m$, they will be designated as $C M_{m}^{i}, C M_{m}^{o}$ and $C M_{m}^{b}$, respectively. 
[ Figure 7 - Canonical model concept ]

The next two paragraphs show how to obtain (i) the canonical models of the PartsSupplier system from its structure and the stochastic processes associated to the individual pieces of equipment, (ii) $f_{T_{D}}(t)$ from the canonical model at the output of the production system, $C M_{a}^{o}$.

\subsection{Determination of the canonical model}

In order to obtain $C M_{S}^{o}$, both the internal behaviour of each cell and the global structure of the production system must be known. To capture this data, two modelling levels local and global - were considered (figure 8). At the local level, models represent the internal behaviour of the cells, whereas global level models represent the overall structure of the production systems. The algorithm for the determination of $C M_{S}^{o}$ explores the idea that the canonical model concept can be applied to the output of any subsystem of the production system, and involves four main steps, as follows:

- firstly, the internal behaviour of each manufacturing cell is analyzed per se, in order to represent the corresponding internal model (figure 8, step1);

- then, the canonical models at the output of the upstream cells are obtained (figure 8, step 2);

- for those cells having an output buffer, the canonical models at their output are determined, from the combination of the internal model of the cell, and the buffer propagation process (figure 8, step 3);

- the final step consists of the determination of the canonical model at the output of the production system, from the combination of the internal model of the final assembly line, and the canonical models and the inputs of the line (figure 8, step 4).

[ Figure 8 - Determination of the canonical model ]

If the production system would contain more stages, the third and fourth stages would be repeated to each additional stage. In fact, as the upstream system is always represented through the standard canonical model, it is possible to always apply the same procedures. The procedures corresponding to these four steps were presented in a 
previous paper (Faria, 2006). They are also summarized in annex 1 in order to support the discussion of the numerical application presented in Section 7.

\subsection{Determination of $f_{T_{D}}(t)$}

Once the canonical model at the output of the production system is known, it is possible to proceed with the determination of the density function of the cumulated downtime $f_{T_{D}}(t)$. This is a complex function that depends on the failure and repair processes of all the manufacturing equipment, but also on the intermediate wip buffers that delay the propagation of the failures. If $n$ is the number of failures that occurred during a mission time frame (e.g., a working day) and $t_{f_{i}}$ is the duration of the ith failure, the total downtime of the production system, $T_{D}$, is given by:

$$
\mathrm{T}_{\mathrm{D}}=\sum_{\mathrm{i}=1}^{\mathrm{n}} \mathrm{t}_{\mathrm{f}_{\mathrm{i}}}
$$

Therefore, $T_{D}$ depends on two random variables: the number of failures that occurred during a mission, and the duration of those failures. If $P_{n f}(n)$ is the probability that the number of failures is $n$, and $T_{n}$ is the random variable representing the cumulated duration of $\mathrm{n}$ failures, then $f_{T_{D}}(t)$ is obtained from:

$$
f_{T_{D}}(t)=\sum_{n} P_{n f}(n) \times f_{T_{n}}(t), \text { for } t>0
$$

where $f_{T_{n}}(t)$ is density function of $T_{n}$. As the density function of the duration of each failure, $t_{f_{i}}$, coincides with that of the reposition process of the canonical model at the output of the system, $f_{\rho_{S}^{o}}(t)$, then:

$$
f_{T_{n}}(t)=\int_{0}^{t} f_{\rho_{S}^{o}}\left(t_{1}\right) \int_{t_{1}}^{t} f_{\rho_{S}^{o}}\left(t_{2}-t_{1}\right) \ldots \int_{t_{n-2}}^{t} f_{\rho_{S}^{o}}\left(t_{n-1}-t_{n-2}\right) f_{\rho_{S}^{o}}\left(t-t_{n-1}\right) d t_{n-1} . . d t_{2} d t_{1}
$$

For large values of $\mathrm{n}, f_{T_{D}}(t)$ becomes very complex and difficult to handle. However, in practical applications, the probability $P_{n f}(n)$ decreases rapidly with $n$, and so only the first terms of the sum have to be considered. In fact, due to the generalized implementation of the total quality and total productive maintenance principles and tools during the past decades (see, for example, Brah (2004), Da Silva (2005), or 
Rungtusanatham (2005) for a presentation of these techniques), the occurrence of more than three failures during the time frame of a mission is very unlikely.

To evaluate the probabilities $P_{n f}(n)$, consider the model in figure 9. This model represents the failure and operating states of the production system during a working period: state $s_{0}$ corresponds to the initial state of the system (it is assumed that the system is in its normal operating state at the beginning of a new mission); $s_{f i}$ corresponds to the state achieved after the occurrence of the ith failure; and $s_{0 i}$ corresponds to the state after the execution of the ith reposition. Processes $p_{\Lambda}$ and $p_{\rho}$ are the failure and the reposition processes, respectively, and $p_{T}$ is a deterministic process representing the mission time frame. As the mean of the reposition process is normally much smaller than that of the failure process, the simpler model of figure $9 . \mathrm{b}$ can be employed.

\section{[ Figure 9 - Model for the determination of $P_{n f}(n)$ ]}

According to this model, the probability of the occurrence of $i$ or more failures during $T$ is given by:

$$
P_{n f}(\geq i)=\int_{0}^{T} f_{\Lambda}\left(t_{1}\right) \int_{t_{1}}^{T} f_{\Lambda}\left(t_{2}-t_{1}\right) \ldots \int_{t_{n-1}}^{T} f_{\Lambda}\left(t_{n}-t_{n-1}\right) d t_{n} \ldots d t_{2} d t_{1}
$$

where $f_{\Lambda}(t)=\Lambda e^{-\Lambda t}$ is the failure process of $C M_{S}^{o}$. If $P_{n f}(\geq i)$ is evaluated for $\mathrm{i}=1 \ldots \mathrm{n}$ where $P_{n f}(\geq k)<\varepsilon$ (in which $\varepsilon$ is a constant that can be chosen to be arbitrarily small) then the probability $P_{n f}(n)$ can be obtained from:

$$
P_{n f}(n)=\left\{\begin{array}{l}
0, \quad \text { if } n \geq k \\
P_{n f}(\geq n)-\sum_{j=n+1}^{k} P_{n f}(j), \quad \text { if } n<k
\end{array}\right.
$$

The set of expressions (16) to (19) allow the density function $f_{T_{D}}(t)$ to be obtained from the failure and the reposition processes of the canonical model. Its practical application will be illustrated in the next Section. 


\section{Numerical application}

The procedures presented so far can be used to analyze several aspects of the design of production systems, such as the overall layout of the plant, the maintenance resources and policies, or the redundancy of manufacturing equipment. Hereafter, they will be employed to assist the design of the output buffer of the PartsSupplier production system. Firstly, consideration will be given to the buffer that minimizes the overall production costs, following the cost model introduced in Section 4. Then, the buffer will be designed in order to guarantee a specified quality of service level. In the first instance, the service level is specified in terms of the maximum number of delivery failures per year. Then, the service level will be specified in terms of the maximum cumulated quantity not delivered per year. Before the presentation of the numerical results, it may be useful to briefly review the main procedures of the approach.

\subsection{Analysis procedure summary}

As summarized in table 1, the approach involves three main steps, the first one of which consists of the determination of the production system canonical model, according to the procedure introduced in paragraph 6.1 and the formulae summarized in annex 1 . The second step consists of the determination of the density function. Firstly, the distribution of the random variable $n_{f}$ corresponding to the number of failures occurred during the time frame of the missions is determined from expression (19). Then, $f_{T_{D}}(t)$ is obtained from (16) and (17). The third step consists of the evaluation of the relevant business model, which may be the cost model or the quality of service models introduced in Sections 4 and 5. Once the corresponding expressions are obtained, the models may be evaluated using general purpose mathematical tools such as those presented in Char (1991) or Wolfram (1991).

\section{[ Table 1 - Evaluation procedure steps ]}

The first two steps of the evaluation procedure (corresponding to the reliability model) are identical for the three situations that will be considered. Therefore, they will be presented just once in paragraphs 7.2 and 7.3. Next, the third step will be presented for each one of the three design situations. This way, depending on the performance 
attributes that are to be analyzed in a particular study, one or more business models will be applied on top of the common reliability. As an explanatory note, it should be remarked that the formulae associated to the evaluation approach will be applied in the next Section following a sequence (canonical model $\rightarrow$ density function $\rightarrow$ business models) different from the one that was considered in Sections 4 to 6 (business model $\rightarrow$ canonical model $\rightarrow$ density function) because this latter sequence provides a better understanding of the concepts involved.

\subsection{Determination of the canonical model}

According to the above mentioned procedure, the first and second steps consist of the determination of the internal and output canonical models of the manufacturing cells, using expressions (A1) in annex 1. The input data for these steps are the internal behaviour models of the manufacturing units (sketched in figure A3), and the distributions of the stochastic processes (provided in table A1). These canonical models are represented in table 2 . The second step consists of the determination of the canonical models at the output of the wip buffers, $C M_{c}^{b}$, using expressions A2 and A4. In the PartsSupplier systems, just cell 3 has an output buffer. The corresponding model is also presented in table 2.

[ Table 2 - Cells canonical models ]

The forth step consists of the combination of the internal model of the assembly line, and the models of the upstream cells, i.e., the models of cell $_{1}$ and $\mathrm{cell}_{2}$, and the model of the wip buffer at the output of $\mathrm{cell}_{3}$, in order to obtain the canonical model at the output of the production system $C M_{S}{ }^{o}$, as shown in table 3. It should be noted that, in spite of their complexity, the determination of these expressions does not present a major practical difficulty because they were obtained using a systematic procedure (that can be fully automated).

[ Table 3 - Assembly line canonical models ] 
The following figure shows several reposition functions regarding these canonical models. Figure 10.a shows the reposition function at the output of the buffer of $\mathrm{cell}_{3}$ (for several wip values), and figure 10.b shows the reposition function at the output of the system $f_{\rho_{c 3}^{b}}(t)$, which is equivalent to $f_{\rho_{a}^{o}}(t)$ versus its three components: $f_{\rho_{c l, 2}^{o}}(t)$, $f_{\rho_{a}^{o}}(t)$ and $f_{\rho_{a}^{i}}(t)$

[ Figure $10-$ Reposition functions ]

\subsection{Determination of the density function $f_{T_{D}}(t)$}

As explained before, the first step to obtain $f_{T_{D}}(t)$ is the determination of probabilities $P_{n f}(\geq n)$. From (18), it becomes:

$$
\mathrm{P}_{\mathrm{nf}}(\geq \mathrm{n})=\int_{0}^{\mathrm{T}} \Lambda_{\mathrm{a}}^{\mathrm{o}} \mathrm{e}^{-\Lambda_{\mathrm{a}}^{\mathrm{o}} \mathrm{t}_{1}} \ldots \int_{\mathrm{t}_{\mathrm{n}-1}}^{\mathrm{T}} \Lambda_{\mathrm{a}}^{\mathrm{o}} \mathrm{e}^{-\Lambda_{\mathrm{a}}^{\mathrm{o}}\left(\mathrm{t}_{1}-\mathrm{t}_{\mathrm{n}-1}\right)} \mathrm{dt}_{\mathrm{n}} \ldots \mathrm{dt}_{2} \mathrm{dt}_{1}
$$

The distribution of the number of failures random variable can now be obtained from:

$$
\mathrm{P}_{\mathrm{nf}}(\mathrm{n})=\mathrm{P}_{\mathrm{nf}}(\geq \mathrm{n}-1)-\mathrm{P}_{\mathrm{nf}}(\geq \mathrm{n})
$$

Figure 11 shows the plots of $P_{n f}(n)$, for $n=0$ to 4 , and for a two hours wip buffer. These plots show that the probability of the occurrence of 3 or more failures during a single workday is very small.

[ Figure 11 - Probability of the number of failures during a single workday ]

This same result is confirmed by figure 12 which shows the plot of $f_{T_{D}}(t)$ when just 1,2 or 3 terms are considered in expression (8). Therefore, only the first 3 terms will be considered:

$$
f_{T_{D}}(t)=\sum_{n=1}^{3} P_{n f}(n) \times f_{T_{n}}(t), \text { for } t>0
$$

or:

$$
\begin{aligned}
f_{T_{D}}(t)=P_{n f}(1) f_{\rho_{a}^{o}}(t) & +P_{n f}(2) \int_{0}^{t} f_{\rho_{a}^{o}}\left(t_{1}\right) f_{\rho_{a}^{o}}\left(t-t_{1}\right) d t_{1}+ \\
& +P_{n f}(3) \int_{0}^{t} f_{\rho_{a}^{o}}\left(t_{1}\right) \int_{t_{1}}^{t} f_{\rho_{a}^{o}}\left(t_{2}-t_{1}\right) f_{\rho_{a}^{o}}\left(t-t_{2}\right) d t_{2} d t_{1}, t>0
\end{aligned}
$$


Once obtained the analytical expression for $f_{T_{D}}(t)$, it may be employed in the business oriented models of the PartsSupplier system as shown in the next paragraphs.

[ Figure 12 - Function $f_{o}^{a}(t)$ for different numbers of failures ]

\subsection{Buffer for the minimal production cost}

This first design analysis corresponds to a direct usage of the cost model introduced in Section 4. The four cost components can be evaluated for different values of the wip and the output buffers from (4) to (7). The corresponding plots are shown in figure 13.

\section{[ Figure 13 - Production losses ]}

Figure 13.a shows the total production cost versus the capacity of the wip buffer $\left(B_{\text {wip }}\right)$ and the capacity of the safety stock output buffer (SS). Figures 13.b and 13.c show the projection of the production cost for several values of $B_{\text {wip }}$ and $S S$. The analysis of this data shows that the minimum cost is $798.34 \mathrm{uc}$, and that this value is obtained for a wip buffer and safety stock equivalent to $3.52 \mathrm{hr}$ and $6,87 \mathrm{hr}$ production at cell $_{3}$ and at the assembly line, respectively. The cost model can also be used to perform sensitivity analysis. As an example, figure 14 shows, for each cost driver, the production costs when that cost driver is doubled or halved and the other drivers remain unchanged.

\section{[ Figure $14-$ Cost drivers sensitivity analysis ]}

The evolution of total production cost versus the mean-time-to-repair of the internal and external repair processes could also be analysed from the same model. This analysis can be extremely useful for the managers of production systems that have to negotiate maintenance contracts with external service suppliers or design the maintenance system (e.g., number of spare parts in stock, implemented diagnosis aid tools, or repairmen's training program). 


\subsection{Buffer for a maximum number of failures}

Here, a different criterion will be considered in the design of the production system: the assurance of a maximum number of delivery failures per year. The corresponding procedure was introduced in Section 5. Figure 15.a shows the plot of $p$ versus the capacity of the wip buffer and the safety stock at the output of the plant, whereas figure 15.b shows the plot of $p$ versus $S S$ for the optimal $B_{\text {wip }}$ determined before (i.e., $B_{\text {wip }}=$ $6,87 \mathrm{hr})$.

[ Figure 15 - Daily probability of failure ]

The probability that the number of failures per year stays below a given number of failures, $N F_{y}$, is given by expression (16). For a given statistical confidence level $\phi$, relationship (16) should be verified to guarantee that the plant respects the specified quality of service. Figure 16.a shows $N F_{y}$ versus the wip and the safety stock, and figure 16.b shows the plot of $N F_{y}$ versus SS assuming $B_{\text {wip }}=6,87 \mathrm{hr}$ and always for $\phi=95 \%$. From this data and for a given specification of the quality of service, the required safety stock can be determined. For example, if the business contract specifies a maximum number of 5 failures per year, a buffer with a capacity equivalent to 6.15 hours of production would have to be implemented. Note that, according to the graphic in figure 16 , the overall production cost corresponding to this design of the buffer is $869.89 \mathrm{uc}$, which is a value significantly higher than the minimum cost obtained in the previous paragraph (798.34 uc). This result could be expected, as the imposition of demanding quality related requirement has a detrimental effect upon the production cost.

[ Figure 16 - Expected number of failures per year ]

\subsection{Buffer for a maximum quantity not delivered}

This paragraph illustrates the application of the model introduced in Section 5, paragraph 2. Figure 17 shows the evolution of $m q_{i}, \sigma q_{i}$ and $Q_{y}$ versus the safety stock. From this data, and given a specified level for the quality of service, it is possible to determine the required stock. For example, if the service specification states that the cumulated quantity not delivered per year should not exceed a quantity equivalent to 50 
hours of production, the minimum safety stock required to ensure this requirement will be 4.82 hours. Expressions (18) and (19) form the business model corresponding to this new type of analysis. In fact, and as before, once both $m q_{i}$ and $\sigma q_{i}$ depend on $S S$ and $f_{T_{D}}(t)$, this expression relates a business oriented performance metrics, that is $Q_{y}^{s p e c}$, to the internal design of the system.

[ Figure 17 - Expected quantity not delivered per year ]

\section{Discussion and conclusions}

In supply chain management, multiple resources are engaged in order to ensure that the right merchandise is produced and distributed to the right locations, at the right time. To minimise lead time and system wide costs, the materials received from the suppliers are often sent directly to the final assembly line. This imposes very high requirements upon the reliability of the deliveries of the suppliers. For a large production system, this reliability depends on multiple factors, from the intrinsic reliability of the equipment and the organisation of the maintenance system, to the layout of the production system, the wip inventory and the safety stocks. Therefore, production systems managers face complex decisions regarding the selection of the appropriate design options that minimize the operational cost and guarantee the service level agreed with their clients. Once a set of design options is identified, managers may want to assess and compare them vis-à-vis with the business requirements.

As exposed in the paper, is our conviction that, despite all the research conducted in this area there is still a need for an integrated framework allowing such shop floor design options to be related to the service level requirements, and we believe that the investigation presented in the paper represents a step forward on this direction. When compared to other approaches reviewed in Section 2, the method presented here possesses some distinctive features that we can hereby distinguish:

- it does not impose any restriction regarding the internal organization of the production systems and it may be applied to different types of layout, with and without intermediate work-in-progress buffers and redundant equipment. 
- it has the ability to deal with non-exponential stochastic processes and non-linear cost and quality of service models.

Existing methods for the analysis and design of production systems often assume (i) a fixed structure, e.g. a series of machines, (ii) a linear function between the internal performance metrics, such as availability or productivity, and the performance at business level and (iii) the "Markovian hypothesis" according to which all the random variables of the systems, such as time-to-failure and time-to-repair are assumed to have exponential distributions. As explained in Section 1, this is not compatible with the mission oriented view of production systems that was adopted here because the cost and the quality of service models are both non-linear functions of the cumulated downtime at the output of the production system, $T_{D}$. As this is a random variable with a high variability, the performance metrics, i.e., cost and quality of service, should be assessed using its density function. In these conditions, the adoption of the usual Markovian hypothesis (e.g., in Zakarian (1997) or Brehm (1996)), may introduce very significant errors in the calculations and, consequently, lead to wrong design decisions (for a detailed discussion on this topic, see Nunes (2002) or Faria (2001)).

The density function of $T_{D}$ is at the core of the new approach. The paper has shown how this function may be obtained from the canonical model and how the production costs and the quality of service may be assessed using this function. The practical application of the approach was illustrated through the numerical example presented in Section 7, concerning the production system of a supplier in the automotive industry. There, a particular attention has been given to the design of the finished product buffer. However, the same approach and the same models could have been applied to analyse other aspects of the production system and compare other design options, e.g., layout, maintenance and redundancy. Moreover, as both the internal reliability models and the business models are analytical models, they constitute a sound basis for sensitivity analysis. This was also exemplified in paragraph 6.4 through an analysis of the impact of the four costs components drivers upon the optimal design of the system.

In any decision process regarding a strategic design issue, several factors have to be taken into account, many of which are not prone to be assessed using analytical tools. For example, the implementation of a finished product buffer may improve the 
responsiveness to unexpected events such as a sudden increase of demand or a shortage of raw material, but it may be hard to assess that responsiveness quantitatively. Therefore, the tools presented in the paper should not be seen as solution, per se, for the analysis and design of production systems. They may be quite effective as a preliminary assessment tool of the main options being considered, but their results should always be complemented by the empirical knowledge of the managers and designers of the production systems.

In the paper, a single product production system was considered but the extension of the approach to multi-product systems is currently being investigated. The assessment of systems that produce several batches with different priority levels and within the same time frames represents a major challenge because the consequences of a particular production depends on production schedule and the production recovery policies. In fact, the consequences of the failures will be different for "fixed pattern mix" shedulling policy and for a "high priority batches first" policy. Also, depending of the recovery policy, after a failure, the production schedule may all be shifted for a time equivalent to the duration of the breakdown, or the schedule may remain unchanged and the batch recovery will take place during the extra time period. Moreover, the consequences of a production breakdown will depend not only on its duration but also on the initial instant of the failure and a breakdown during the production of a high priority batch may impact the delivery of other lower priority batches.

The fundamentals of the approach presented before will remain unchanged but several extensions to the evaluation procedures will be required in order to incorporate the production schedule in the reliability and business models

A second research topic that is being pursued concerns the use of fuzzy sets theory as a tool to contemplate the uncertainty on the production demand and on the distributions of stochastic processes. The rational comes from that fact, very often, the reliability data available are few and uncertain thus undermining the robustness of the decisions based on the reliability models. In the case of the systems being considered here, uncertainty typically regards the parameters of the stochastic distributions and the market demand. In the paper, it was assumed that demand was constant and known. This is a reasonable 
assumption in the automotive industry, where the business contracts usually have a long time span, although such is not most other industries.

As shown in Miranda 1996, the fuzzy sets theory provides a sound theoretical basis to deal with such situations and a combined fuzzy-probabilistic approach may be a suitable a tool to capture the stochastic nature of processes such as failure and repair and the uncertainty ontheir distributions. According to Cai et al. (1991), the reliability and business models of production systems belong to the "profust" class and the standard tools to handle these models are the arithmetic by intervals and the extension principle. However, as showed in Nunes (2005), the application of these techniques to complex models lead to fuzzy results with a very large spreading, so that their practical interest is limited. Therefore, the main research challenge here regards the development of a technique able to propagate the uncertainty from the non-Markovian reliability models to the non-linear business model and to minimize the spreading of the fuzzy results. This way, the features and steps and of the evaluation procedure for fuzzy models will be similar to those of the procedure considered for the crisp models, particularly the ability to deal with non exponential processes. 


\section{References}

Ahmad, A., S. Mehra, et al. (2004). "The perceived impact of JIT implementation on firms' financial/growth performance", Journal of Manufacturing Technology Management 15(2): 118-30.

Ajodhya, D. and Damodar, A., "Age replacement of components during IFR delay time", IEEE Transactions on Reliability, v 53, n 3, September, 2004, p 306-312

Beamon, B., "Measuring supply chain performance", International Journal of Operations and Production Management, 19(3), pp. 275-292, 1999.

Berg, M., Posner, M., Zhao, H. "Production-inventory systems with unreliable machines", Operations Research, Vol. 42, No. 1, p. 111-118, Jan-Feb 1994.

Boyd, D. T., L. Kronk, et al. (2002). "The effects of just-in-time systems on financial accounting metrics", Industrial Management + Data Systems 102(3): 153-64.

Brah, S. and Chong, W. "Relationship between total productive maintenance and performance", International Journal of Production Research, v 42, n 12, Jun 15, 2004, p. 2383-2401

Brehm, E. "System Dependability Assessment Tool", Proceedings of the 2nd IEEE International Conference on Engineering of Complex Computer Systems, Montreal, Canada, (1996).

Buzacott, J. and Zhang, R., "Inventory Management with Asset-Based Financing", Management Science, v 50, n 9, pp. 1274-1292, Sep 2004.Cai, K., Wen, C. and Zhang, M., "Fuzzy variables as a basis for a theory of fuzzy reliablity in the possibility context." Fuzzy Sets and Systems (1991), vol. 42, p. 145-172.

Chan, F., "Performance Measurement in a Supply Chain", International Journal of Advanced Manufacturing Technology (2003) 21:534-548.

Chiang. D., Guo, R., Chen, A. Cheng. M. and Chen., C., "Optimal supply chain configurations in semiconductor manufacturing", International Journal of Production Research, vol. 45, $n^{\circ} 3$, February 2007, pp. 631-651.

Char, Geddes, Gonnet, Leong, Monagan and Watt, Maple V Language Reference Manual, Springer Verlag, New York, 1991.

Chelbi, A. and Ait-Kadi, D., "Analysis of a production/inventory system with randomly failing production unit submitted to regular preventive maintenance", European Journal of Operational Research, v 156, n 3, Aug 1, 2004, p. 712-718.

Chenhall, R., "Strategies of manufacturing flexibility, manufacturing performance measures and organizational performance: an empirical investigation", Integrated Manufacturing Systems, v 7, n 5, 1996, p. 25-32.

Da Silva J., Tadashi, O. and Kikuo, N, "Looking through and beyond the TQM horizon: Lessons learned from world-class companies", TQM Magazine, vol 17, n 1, 2005, p. 6784.

Das, K., Lashkari, R. and Sengupta, S., "Reliability consideration in the design and analysis of cellular manufacturing systems", International Journal of Production Economics 105 (2007) 243-262 
Enginarlar, E., Li, J., Meerkov, S. and Zhang, R., "Buffer capacity for accommodating machine downtime in serial production lines", International Journal of Production Research 40 (2002), no. 3, 601-624.

Faria, J., Matos, M. "An analytical methodology for the dependability evaluation of nonMarkovian systems with multiple components", Journal of Reliability Engineering and System Safety, 74, p. 193-210, 2001.

Faria, J. A., Nunes, E., Matos, M. A., "Optimal dimensioning of work-in-process buffers", International Journal of Production Economics, nº 99/1, January 2006.

Fullerton, R. R., C. S. McWatters, et al. (2003). "An examination of the relationships between JIT and financial performance", Journal of Operations Management 21(4): 383-404.

Giordano, M., Martinelli, F. "Optimal safety stock for unreliable, finite buffer, single machine manfacturing systems", IEEE International Conference on Robotics and Automation, Washington, USA. Vol.3, pp. 2339-2344, May 2002.

Gunasekaran, A, Patel, C. and Tirtiroglu, E., "Performance measurement and metrics in a supply chain environment", International Journal of Operations and Production Management, 21(1/2), p. 71-87, 2001.

Gupta, S. and L-Turki, Y., "Adapting just-in-time manufacturing systems to preventive maintenance interruptions", Production Planning and Control, 1998, vol, Nn 4, 349-59

Hsieh, Y.; Chang, S. and Chang, S., "Design and storage cycle time analysis for the automated storage system with a conveyor and a rotary rack", International Journal of Production Research, vol. 45, nº 22, p. . 5383-5395, November 2007

Holmberg, S., "A system perspective on supply chain measurement", International Journal of Physical Distribution and Logistics Management, 30(10), p. 847-868, 2000.

Hong C. and Jionghua J., "Cost-variability-sensitivity preventive maintenance considering management risks", IIE Transactions, 35, 1091-1101, 2003.

Hu, A., Meerkov, S., "Lean buffering in serial production lines with Bernoulli machines", Mathematical Problems in Engineering, vol 2006, article id 17105, pp. 1-24

Huang, M., Chang, P. and Chou, Y., "Buffer allocation in flow-shop-type production systems with general arrival and service patterns", Computers \& Operations Research 29 (2002) $103-121$

Jüttner, U., Peek, H. and Christopher, M. (2003) Supply chain risk management: outlining an agenda for future research. International Journal of Logistics Research and Applications vol. 6 , p. 197-209.

Kuwaiti, M. and Kay, J., "The role of performance measurement in business process reengineering", International Journal of Operations and Production Management, 20(12), p. 1411-1426, 2000.

Kyriakidis, E. and Dimitrakos, T., "Optimal preventive maintenance of a production system with an intermediate buffer", European Journal of Operational Research 168 (2006) 8699

Lee, H., Padmanabhan, V. and Whang, S. (1997) "Information distortion in a supply chain", Management Science, vol. 43 , p. 546-558. 
Ludema, M., Reliable and invulnerable supply networks, Proceedings of the IEEE International Conference on Service Operations and Logistics, and Informatics, p. 528-533, Shanghai, China, 2006

Mahadevan B., Narendran, T. "Buffer levels and choice of material handling device in Flexible Manufacturing Systems", European Journal of Operational Research, p.166-176, 1969.

Maksoud, A., Dugdale, D. and Luther R., "Non-financial performance measurement in manufacturing companies", The British Accounting Review 37 (2005) 261-297.

Miranda, V., "Fuzzy Reliability Analysis of Power Systems" Proceedings of PSCC'96, Dresden, Germany, 1996.

Moinzadeh, k. and Aggarwal, P., "Analysis of a production/inventory system subject to random disruptions” Management Science, nol. 43, nº. 11, p. 1577-1588, November 1997.

Murphy, J. C. and S. L. Braund (1990). "Management accounting and new manufacturing technology", Management Accounting: 38-40.

Nunes, E., Faria, J. A., Matos, M. A. "A comparative analysis of dependability assessment methodologies" Proceedings of the 3rd ESREL Conference, Lyon, France, May 2002.

Nunes, E., System reliability with non markovian proc-esses and with fuzzy parameters, $\mathrm{PhD}$. Thesis (in Portuguese), (2005) University of Porto, Portugal.

Qi, L.; Shen, Z., "A supply chain design model with unreliable supply", Proceedings of the Institute of Industrial Engineers Conference, Atlanta, United States

Pandya, K. V. and J. Boyd (1995). "Appraisal of JIT using financial measures", International Journal of Operations \& Production Management 15(9): 200-9.

Reiner, G. and Hofmann, P., "Efficiency analysis of supply chain processes", International Journal of Production Research, Vol. 44, No. 23, 1 December 2006, 5065-5087

Rice, J. and Caniato, F. "Building a secure and resilient supply network", Supply Chain Managemente Review. 7 , p. 22-30.

Riddalls, C., Bennett, S. and Tipi, N. "Modeling the dynamics of supply chains", International Journal of Systems Science, 31, p. 969-976.

Rolstandas, A., "Performance Measurement: a Business Process Benchmarking Approach", Chapman and Hall, New York, USA, 1995.

Rungtusanatham, M., Forza, C., Koka, B., Salvador, F. and Nie, "TQM across multiple countries: Convergence Hypothesis versus National Specificity arguments", Journal of Operations Management, v 23, n 1, January, 2005, p. 43-63.

Saaty, T., "How to make a decision: the analytic hierarchy process", European Journal of Operational Research, 48(1), p. 9-26, 1990.

Schmitz, J., Platts, K., "Supplier logistics performance measurement: Indications from a study in the a utomotive industry", International Journal of Production Economics 89 (2004) 231-243

Supply-chain Council, Supply-chain Operations Reference-model, (1996), USA.

Shiau, Y., "Quick decision-making support for inspection allocation planning with rapidly changing customer requirements" International Journal of Advanced Manufacturing Technology, v 22, n 9-10, p. 633-640, 2003. 
Shrivastava, R. Mohanty, R. and Lakhe, R., "Linkages between total quality management and organisational performance: an empirical study for Indian industry", Production Planning \& Control, Vol. 17, No. 1, January 2006, 13-30

Van Hoek, R., "Measuring the unmeasurable - measuring and improving performance in the supply chain", Supply Chain Management, 3(4), p. 187-192, 1998.

Van Ryzin, G., Lou, S., Gershwin, S. "Production control for tandem two-machines system", Transactions of the Institute of Electrical Engineers, Vol. 25, No. 5, p. 5-20, September 1993.

White, R., Pearson, J. and Wilson, J., "JIT manufacturing: a survey of implementations in small and alarge US manufacturers", Management Science, vot. 45, n 1, January 1999.

Wiendahl, H.; Cieminski, G., "A systematic approach for ensuring the logistic process reliability of supply chains", CIRP Annals - Manufacturing Technology, vol. 52, $\mathrm{n}^{\mathrm{o}}$ 1, p. 375-380, 2003

Wolfram, S. Mathematic: A system for doing Mathematics by Computer, Second Edition, Reading, MA Addison-Wesley, 1991.

Wu, T., Blackhurst, J. and O'grady, P., "Methodology for supply chain disruption analysis", International Journal of Production Research, Volume 45, Issue 7 April 2007 , pages $1665-1682$

Yucesan, E. and Xaview, D., "Theory and methodology: lead times, order release mechanisms, and customer service", European Journal of Operational Research, 120, p. 118-130, 2000 .

Zakarian, A. and Kusiak, A. "Modeling Manufacturing Dependability", Transactions on Robotics and Automation, vol.13, n 2, IEEE, April 1997. 


\section{Annex 1: Canonical models}

In Faria (2006), a detailed analysis of the procedures for the determination of the production systems canonical models is presented. A summary of the formulae relevant for the analysis of the situations found in the PartsSupplier system (Section 7 and annex

2) will be discussed here, namely the determination of:

- the models of the non-redundant upstream manufacturing cells;

- the model at the output of the wip buffer;

- the internal model of the redundant assembly line;

- the output model of the multi-cell production system.

\section{A1.1. Non redundant cells}

Consider a cell $c$ that is composed of $n$ non-redundant machines, each one with a single failure/repair process pair. The parameters of the equivalent internal canonical model are given by the following expressions, where $\lambda_{j}$ is the failure rate of machine $j$, and $f_{\mu_{j}}(t)$ is the density function of its repair process, $p_{\mu_{j}}$ :

$$
\begin{aligned}
& \Lambda_{\mathrm{c}}^{\mathrm{i}}=\mathrm{P}_{0} \sum_{\mathrm{j}=1}^{\mathrm{k}} \lambda_{\mathrm{j}} \text { with } \mathrm{P}_{0}=\frac{1}{1+\sum_{\mathrm{j}=1}^{\mathrm{k}} \lambda_{\mathrm{j}} \mathrm{m}_{\mu_{\mathrm{j}}}} \text { and } \mathrm{m}_{\mu_{\mathrm{j}}}=\int_{0}^{\infty} \mathrm{tf}_{\mu_{\mathrm{j}}}(\mathrm{t}) \mathrm{dt} \\
& \mathrm{f}_{\rho_{\mathrm{c}}^{\mathrm{i}}}(\mathrm{t})=\sum_{\mathrm{j}=1}^{\mathrm{k}} \frac{\lambda_{\mathrm{j}}}{\Lambda_{\mathrm{c}}^{\mathrm{i}}} \mathrm{f}_{\mu_{\mathrm{j}}}(\mathrm{t})
\end{aligned}
$$

\section{A1.2. Wip buffer}

Suppose a buffer $b$ at the output of a cell where $p_{b}$ is the process that models the propagation of the failures from the input to the output of $b$. The failure rate $\Lambda_{c}^{b}$ of the canonical model at the output of the buffer comes from the product of the frequency of arrival to state $s_{1}$ (corresponding to a failure at the output of the cell) and the probability of transition to state $s_{1}$, (corresponding to a failure at the output of the buffer). If $f_{b}(t)$ is the density function of the buffer process: 


$$
\Lambda_{\mathrm{c}}^{\mathrm{b}}=\Lambda_{\mathrm{c}}^{\mathrm{i}} \int_{0}^{\infty} \mathrm{f}_{\mathrm{b}}\left(\mathrm{t}_{1}\right) \int_{\mathrm{t}_{1}}^{\infty} \mathrm{f}_{\mathrm{p}_{\mathrm{c}}}\left(\mathrm{t}_{2}\right) d \mathrm{t}_{2} \mathrm{dt}_{1}
$$

The density function of the reposition process comes from the ratio between the density function of the time of residence in state $s_{1}$, given that the system has arrived at $s_{1}$ :

$$
\int_{0}^{\infty} f_{b}\left(t_{1}\right) f_{\rho_{c}^{i}}\left(t+t_{1}\right) d t_{1}
$$

and the probability of transition $s_{1} \rightarrow s_{1}$. Thus:

$$
\mathrm{f}_{\rho_{\mathrm{c}}^{\mathrm{b}}}(\mathrm{t})=\frac{\int_{0}^{\infty} \mathrm{f}_{\mathrm{b}}\left(\mathrm{t}_{1}\right) \mathrm{f}_{\rho_{\mathrm{c}}^{\mathrm{i}}}\left(\mathrm{t}+\mathrm{t}_{1}\right) d \mathrm{t}_{1}}{\Lambda_{\mathrm{c}}^{\mathrm{b}} / \Lambda_{\mathrm{c}}^{\mathrm{i}}}
$$

\section{A1.3. Passive redundancy}

Consider a cell composed of two machines, one of which is in passive redundancy, whose behaviour is represented in Figure A1. Firstly, for each down state in the original graph, the expressions for the frequency of arrival and for the distribution of the reposition process are determined. Then, $\Lambda_{c}^{i}$ and $f_{\rho_{c}^{i}}(t)$ may be determined using expressions (A1) and (A2). The relevant expressions for the first failure state of figure $\mathrm{A} 1, s_{1}$, are:

$$
\begin{aligned}
& \mathrm{P}_{0}=\frac{1}{1+\lambda\left(\mathrm{m}_{\xi}+\mathrm{m}_{\mu}\right)} \\
& \Lambda_{\mathrm{s} 1}=\lambda_{1} \mathrm{P}_{0} \\
& \mathrm{f}_{\rho_{\mathrm{s} 1}}(\mathrm{t})=\mathrm{f}_{\xi}(\mathrm{t})
\end{aligned}
$$

For the second failure state, $s_{3}$, the equivalent failure rate and reposition process are:

$$
\begin{gathered}
\Lambda_{\mathrm{s} 3}=\Lambda_{\mathrm{s} 1} \int_{0}^{\infty} \mathrm{f}_{\lambda_{2}}\left(\mathrm{t}_{1}\right) \int_{\mathrm{t}_{1}}^{\infty} \mathrm{f}_{\mu}\left(\mathrm{t}_{2}\right) d \mathrm{t}_{2} \mathrm{dt}_{1} \\
\mathrm{f}_{\rho_{\mathrm{s} 3}}(\mathrm{t})=\frac{\int_{0}^{\infty} \mathrm{f}_{\lambda}\left(\mathrm{t}_{1}\right) \mathrm{f}_{\mu}\left(\mathrm{t}+\mathrm{t}_{1}\right) d \mathrm{t}_{1}}{\int_{0}^{\infty} \mathrm{f}_{\lambda}\left(\mathrm{t}_{1}\right) \int_{\mathrm{t}_{1}}^{\infty} \mathrm{f}_{\mu}\left(\mathrm{t}_{2}\right) d \mathrm{t}_{2} \mathrm{dt}_{1}}
\end{gathered}
$$

The equivalent internal model of the cell (figure A1.c) can be obtained as before from:

$$
\Lambda_{\mathrm{c}}^{\mathrm{i}}=\Lambda_{\mathrm{s} 1}+\Lambda_{\mathrm{s} 3}
$$




$$
\mathrm{f}_{\rho_{\mathrm{c}}^{\mathrm{i}}}(\mathrm{t})=\frac{\Lambda_{\mathrm{s} 1}}{\Lambda_{\mathrm{c}}^{\mathrm{i}}} \mathrm{f}_{\rho_{\mathrm{s} 1}}(\mathrm{t})+\frac{\Lambda_{\mathrm{s} 3}}{\Lambda_{\mathrm{c}}^{\mathrm{i}}} \mathrm{f}_{\rho_{\mathrm{s} 3}}(\mathrm{t})
$$

[ Figure A1 - Internal model of a redundant cell ]

\section{A1.4. Multiple cells}

Now consider the manufacturing cell $_{3}$ of the system sketched in figure A2. The production halting at the output of this cell has an endogenous component due to the failures of the internal equipment of the cell, and an exogenous component due to the material shortages at its inputs $\left(C M_{c 1}^{b}\right.$ and $\left.C M_{c 2}^{b}\right)$. The failure rate at the output of cell $_{3}$ comes from the sum of the endogenous and exogenous failures rates, that is:

$$
\Lambda_{3}^{\mathrm{o}}=\Lambda_{1}^{\mathrm{b}}+\Lambda_{2}^{\mathrm{b}}+\Lambda_{3}^{\mathrm{i}}
$$

Regarding the reposition process, its distribution is obtained from the weighted average of the three reposition processes involved, that is, from:

$$
\mathrm{f}_{\rho_{3}^{\mathrm{o}}}(\mathrm{t})=\frac{\Lambda_{1}^{\mathrm{b}}}{\Lambda_{3}^{\mathrm{o}}} \mathrm{f}_{\rho_{1}^{\mathrm{b}}}(\mathrm{t})+\frac{\Lambda_{2}^{\mathrm{b}}}{\Lambda_{3}^{\mathrm{o}}} \mathrm{f}_{\rho_{2}^{\mathrm{b}}}(\mathrm{t})+\frac{\Lambda_{3}^{\mathrm{i}}}{\Lambda_{3}^{\mathrm{o}}} \mathrm{f}_{\rho_{3}^{\mathrm{i}}}(\mathrm{t})
$$

[ Figure A2 - Multi-cell canonical model ]

\section{Annex 2 - Reliability data}

This annex presents the reliability data of the PartsSupplier system required by the numerical examples provided in Section 7 of the paper. For the sake of simplicity, cell $_{1}$ and cell $_{2}$ are assumed to have $n$ identical machines, each one submitted to a single failure/repair process $p_{\lambda 1} / p_{\mu l}$ (figure A3.a). The failure processes are assumed to have exponential distributions. For the repair processes a distribution with a lower variability $\left(2^{\text {nd }}\right.$ order Erlang) will be employed.

[ Figure A3 - PartsSupplier internal models ] 
As mentioned in the presentation of the PartsSupplier systems (Section 3), cell $_{3}$ contains 3 machines whose repair demands external maintenance resources, and 2 machines repaired in-house. Therefore, two failure/repair processes will be considered for this cell: $p_{\lambda 2} / p_{\mu 2}$ for the machines repaired in-house, and $p_{\lambda 3} / p_{\mu 3}$ for those requiring the intervention of an external technician, or the ordering of spare parts from an external supplier (figure A3.b). The internal repair processes are assumed to have exponential distributions, but for external repair processes, a $3^{\text {rd }}$ order Erlang distribution will be employed, because PartsSupplier has settled maintenance contracts with external suppliers that impose a maximum fixed lead-time and so the variability of the repair time random variable is lower.

The wip buffer between cell $_{3}$ and the assembly line is assumed to have a constant content. Thus, it will introduce a deterministic delay in the propagation of the failures to the output. The assembly line contains 5 workplaces, three of which in passive so that, when a failure occurs, a reconfiguration procedure is engaged in order to activate a redundant machine (figure A3.c). As this procedure involves a pre-determined sequence of operation, its execution time presents a low variability and so it will be represented by 2 order Erlang distribution. The distributions of the stochastic processes of the four manufacturing units are summarized in table A1.

\section{[ Table A1 - Density functions ]}

Finally, the cost drivers presented in table A2 will be considered in the cost model of the PartsSupplier system. All the cost-related data considered in this paper will be expressed in a standard unit of cost $u c$ that, in practical applications, will typically range between 2,000 and $10,000 €$.

[ Table A2 - Cost drivers ] 


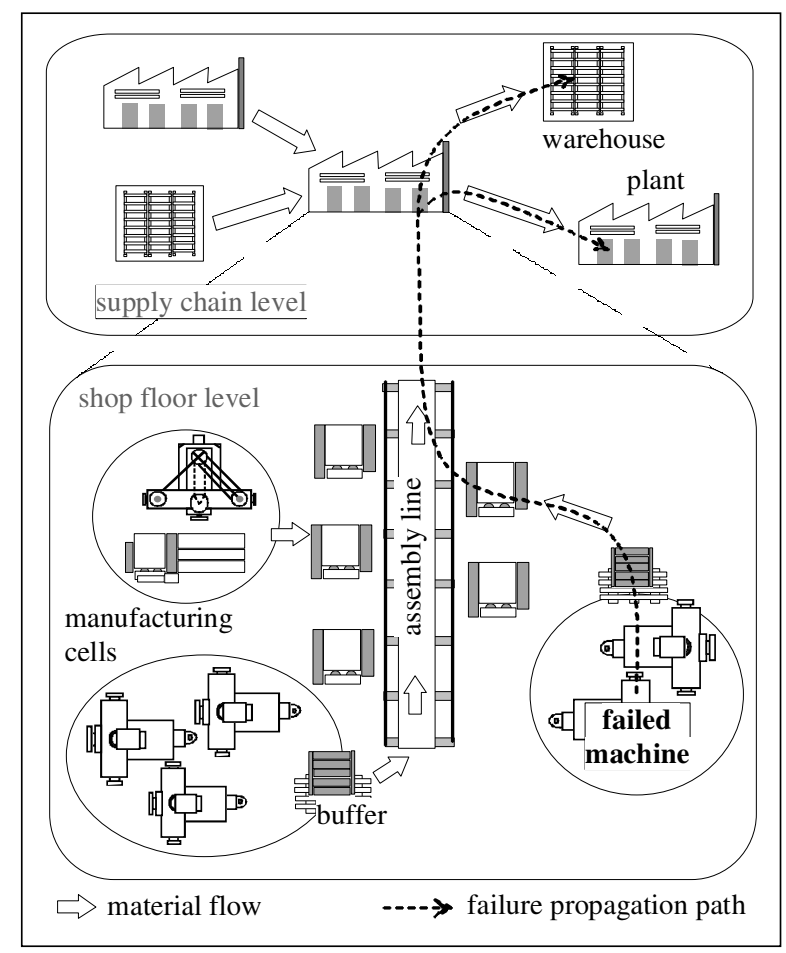

Figure 1 - Failure propagation 


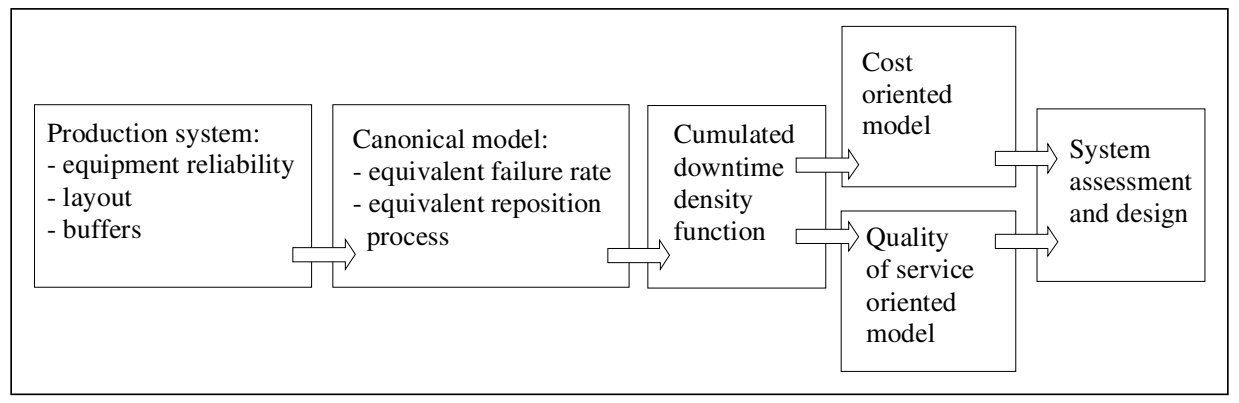

Figure 2 - Analysis and design process overview 


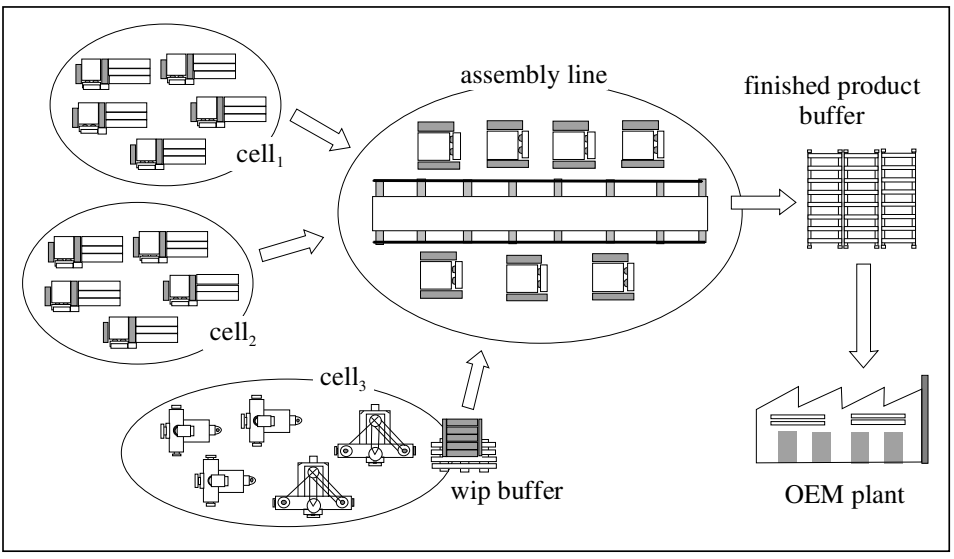

Figure 3 - The PartsSupplier production system 


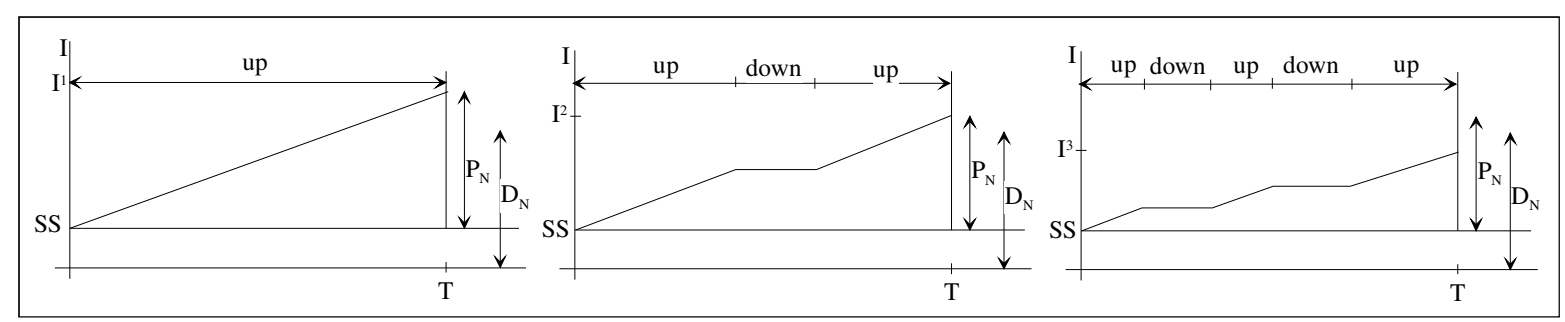

Figure 4 - Evolution of the content of the buffer 


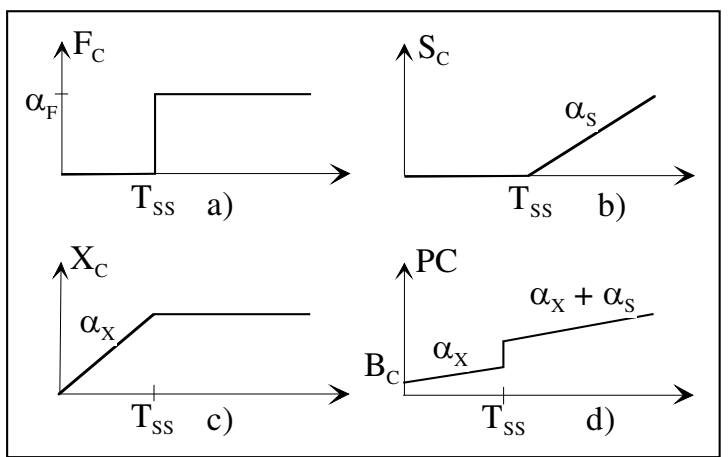

Figure 5 - Graphical representation of the production costs 


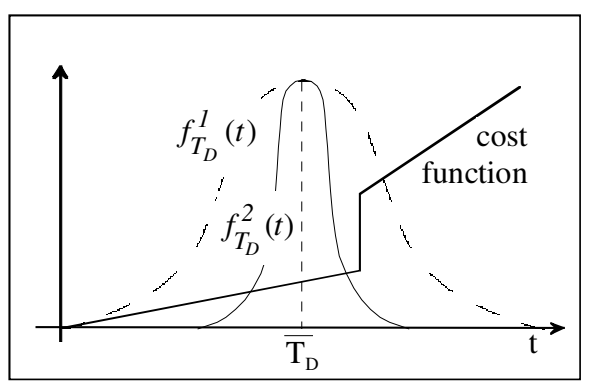

Figure 6 - Evaluation of non-linear cost models 


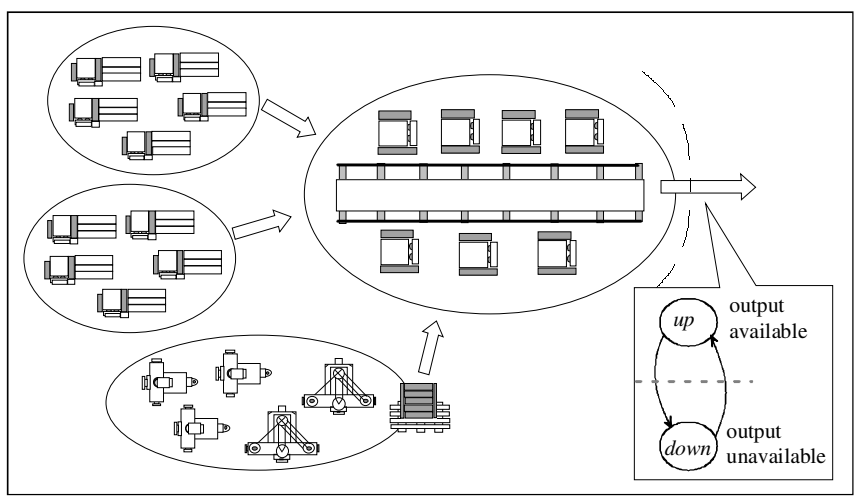

Figure 7 - Canonical model concept 


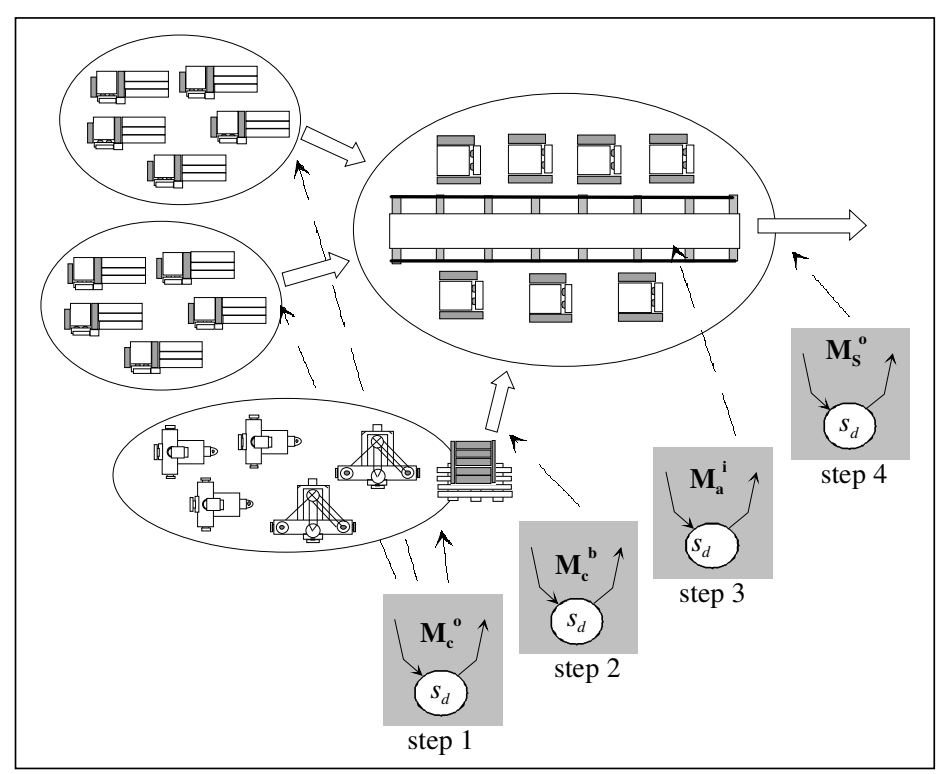

Figure 8 - Determination of the canonical model 


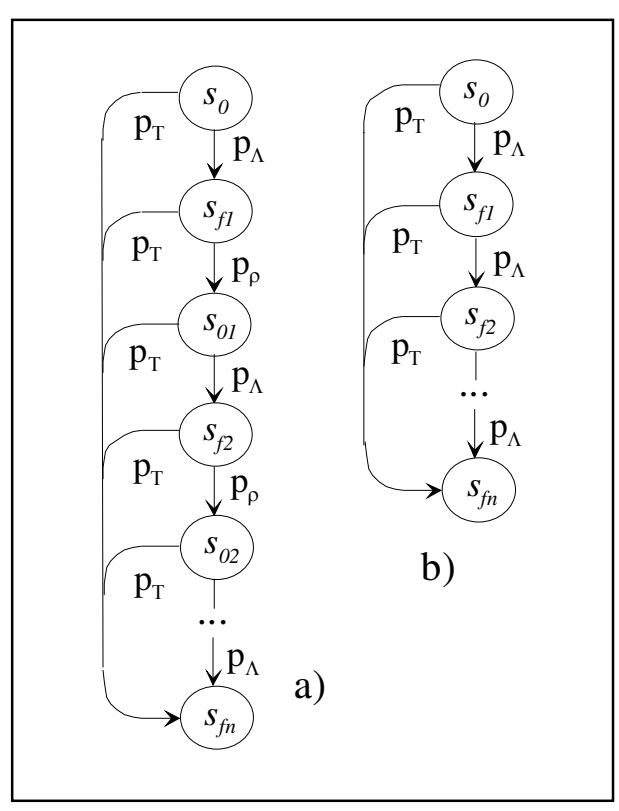

Figure 9 - Model for the determination of $P_{n f}(n)$ 
Table 1 - Evaluation procedure steps

1. Obtain the canonical model of the production system

- Obtain the internal model for all the manufacturing cells

- Obtain the canonical models for the upstream cells

- Obtain the canonical models for the downstream cells

2. Obtain the cumulated halting time

- $\quad$ Obtain the distribution of the number of failures random variable $n f$

- Obtain the density function of the cumulated halting time $f_{T_{H}}(t)$

3. Evaluate the business model

Cost model Quality of service models

- Delivery failure penalties: $c_{F} \int_{S S}^{T} f_{T_{D}}(t) d T_{H}$

- Loss of sales:

- Maximum number of failures $c_{\rho} \int_{s s}^{T} f_{T_{D}}(t)\left(T_{D}-S S\right) d T_{D}$

- Extra working time: $\sum_{n=1}^{N F_{y}^{\text {spec }}}\left(\begin{array}{c}n d_{y} \\ n\end{array}\right)\left(\int_{S S}^{T} f_{T_{D}}(t) d t\right)^{n}\left(1-\int_{S S}^{T} f_{T_{D}}(t) d t\right)^{n d_{y}-n}>\phi$ $c_{\mathrm{XT}} \sum_{\mathrm{n}=1}^{\mathrm{m}} \int_{\mathrm{n}-1}^{\mathrm{n}} \mathrm{n} \mathrm{f}_{\mathrm{T}_{\mathrm{D}}}(\mathrm{t}) \mathrm{dT}_{\mathrm{D}}$

- Maximum quantity not delivered

- Safety stock: $\mathrm{c}_{\mathrm{B}} \mathrm{SS}$ 
Table 2 - Cells canonical models

\begin{tabular}{|c|}
\hline Cell $_{1}$ and Cell 2 \\
\hline $\begin{array}{l}\Lambda_{1,2}^{\mathrm{o}}=\Lambda_{1,2}^{\mathrm{i}}=\frac{\lambda_{1}}{1+\lambda_{1} \mathrm{~m}_{\mu_{1}}} \\
\mathrm{f}_{\rho_{1,2}^{0}}(\mathrm{t})=\mathrm{f}_{\rho_{1,2}^{\mathrm{i}}}(\mathrm{t})=\mathrm{f}_{\mu_{1}}(\mathrm{t})\end{array}$ \\
\hline $\mathrm{Cell}_{3}$ \\
\hline $\begin{array}{l}\Lambda_{3}^{\mathrm{o}}=\Lambda_{3}^{\mathrm{i}}=\frac{\lambda_{2}+\lambda_{3}}{1+\mathrm{r}_{\lambda_{2}} \mathrm{~m}_{\mu_{2}}+\mathrm{r}_{\lambda_{3}} \mathrm{~m}_{\mu_{3}}} \\
\mathrm{f}_{\rho_{3}^{\mathrm{o}}}(\mathrm{t})=\mathrm{f}_{\rho_{3}^{\prime}}(\mathrm{t})=\frac{\mathrm{r}_{\lambda_{2}}}{\Lambda_{3}^{\mathrm{o}}} \mu_{2}(\mathrm{t})+\frac{\mathrm{r}_{\lambda_{3}}}{\Lambda_{3}^{\mathrm{o}}} \mu_{3}(\mathrm{t})\end{array}$ \\
\hline Wip buffer \\
\hline $\begin{array}{l}\Lambda_{3}^{\mathrm{b}}=\Lambda_{3}^{\mathrm{o}} \int_{\mathrm{T}_{\mathrm{B}}}^{\infty} \mathrm{f}_{\rho_{3}^{\mathrm{o}}}(\mathrm{t}) \mathrm{dt} \\
\mathrm{f}_{\rho_{3}^{\mathrm{b}}}(\mathrm{t})=\frac{\mathrm{f}_{\rho_{3}^{\mathrm{o}}}(\mathrm{t})\left(\mathrm{B}_{\text {wip }}+\mathrm{t}\right)}{\int_{\mathrm{T}_{\mathrm{B}}}^{\infty} \mathrm{f}_{\rho_{3}^{\mathrm{o}}}(\tau) \mathrm{d} \tau}\end{array}$ \\
\hline
\end{tabular}


Table 3 - Assembly line canonical models

$$
\begin{aligned}
& \text { Internal model } \\
& \Lambda_{a}^{\mathrm{i}}=\lambda_{5}+\lambda_{4}\left(1+\int_{0}^{\infty} \lambda_{4} \mathrm{e}^{-\lambda_{4} \mathrm{t}_{1}} \int_{\mathrm{t}_{1}}^{\infty} \mu_{4}(\tau) \mathrm{d} \tau \mathrm{dt}_{1}\right) \\
& \mathrm{f}_{\rho_{\mathrm{a}}^{\mathrm{i}}}(\mathrm{t})=\frac{\lambda_{5}}{\Lambda_{\mathrm{a}}^{\mathrm{i}}} \mathrm{f}_{\mu_{5}}(\mathrm{t})+\frac{\lambda_{4}}{\Lambda_{\mathrm{a}}^{\mathrm{i}}} \xi(\mathrm{t})+\frac{\lambda_{4}}{\Lambda_{\mathrm{a}}^{\mathrm{i}}} \frac{\int_{0}^{\mathrm{t}} \lambda_{4} \mathrm{e}^{-\lambda_{4} \tau_{\mathrm{f}}} \mathrm{f}_{\mu_{4}}(\mathrm{t}-\tau) \mathrm{d} \tau}{\int_{0}^{\mathrm{t}} \lambda_{4} \mathrm{e}^{-\lambda_{4} \tau} \mathrm{d} \tau} \\
& \Lambda_{\mathrm{a}}^{\mathrm{o}}=2 \Lambda_{1,2}^{\mathrm{o}}+\Lambda_{1,2}^{\mathrm{b}}+\frac{\left(1-\Lambda_{\mathrm{a}}^{\mathrm{i}} \mathrm{m}_{\rho_{\mathrm{a}}^{\mathrm{i}}}\right)}{\left.\left(1-\Lambda_{\mathrm{a}}^{\mathrm{i}} \mathrm{m}_{\rho^{\mathrm{i}}}\right)+2 \Lambda_{1,2}^{\mathrm{o}} \mathrm{m}_{\rho_{\mathrm{p}, 2}}+\Lambda_{3}^{\mathrm{b}} \mathrm{m}_{\rho_{3}^{\mathrm{b}}}\right)} \Lambda_{\mathrm{a}}^{\mathrm{i}} \\
& \mathrm{f}_{\rho_{\mathrm{a}}^{\mathrm{o}}}(\mathrm{t})=2 \frac{\Lambda_{1,2}^{\mathrm{o}}}{\Lambda_{\mathrm{a}}^{\mathrm{o}}} \mathrm{f}_{\rho_{1,2}^{o}}(\mathrm{t})+\frac{\Lambda_{3}^{\mathrm{b}}}{\Lambda_{\mathrm{a}}^{\mathrm{o}}} \mathrm{f}_{\rho_{3}^{\mathrm{b}}}(\mathrm{t})+\frac{\Lambda_{\mathrm{a}}^{\mathrm{i}}}{\Lambda_{\mathrm{a}}^{\mathrm{o}}} \mathrm{f}_{\rho_{\mathrm{a}}^{\mathrm{i}}}(\mathrm{t})
\end{aligned}
$$




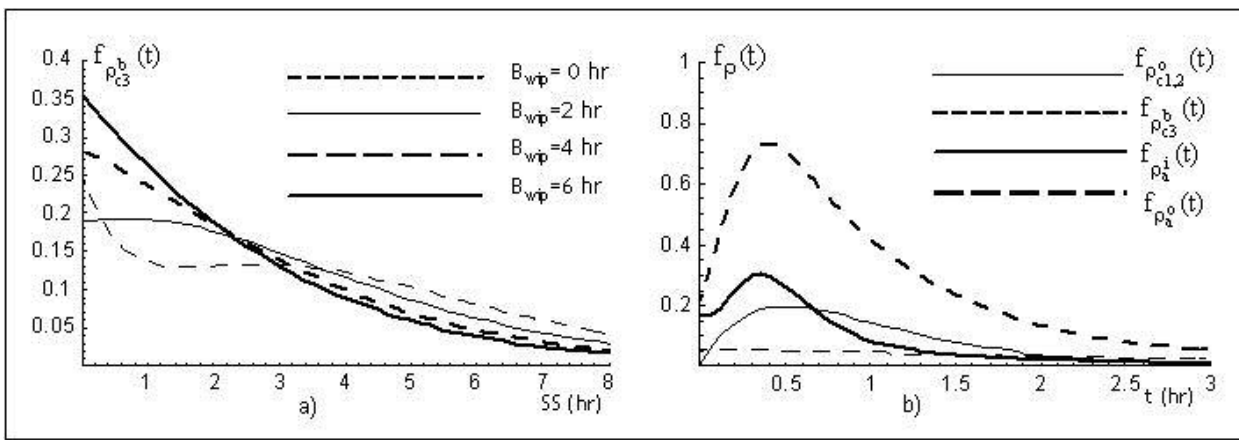

Figure 10 - Reposition functions 


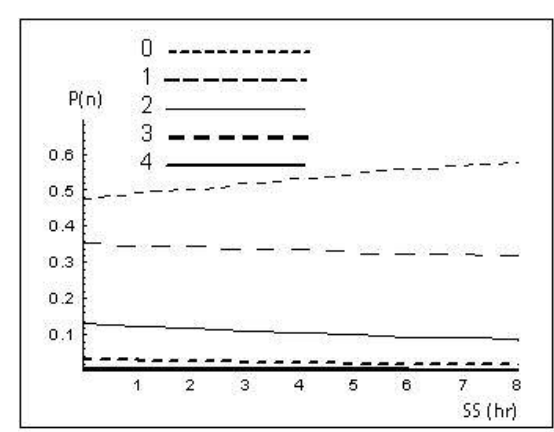

Figure 11 - Probability of the number of failures during a single workday 


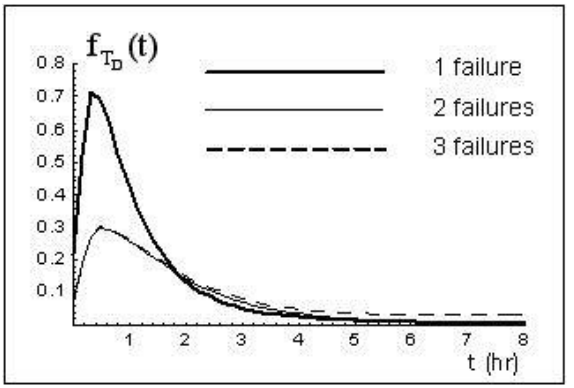

Figure 12 - Function $f_{o}^{a}(t)$ for different numbers of failures 


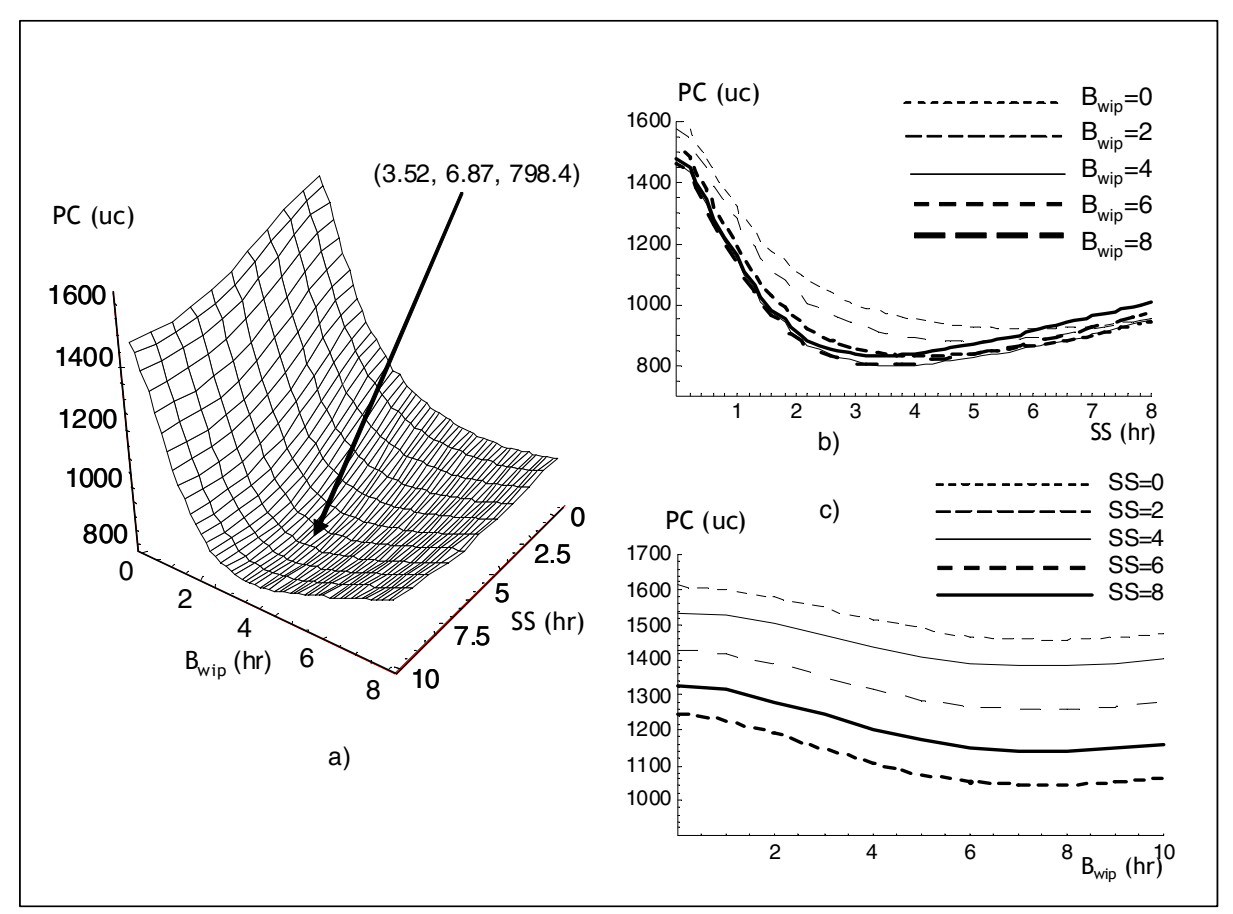

Figure 13 - Production losses 


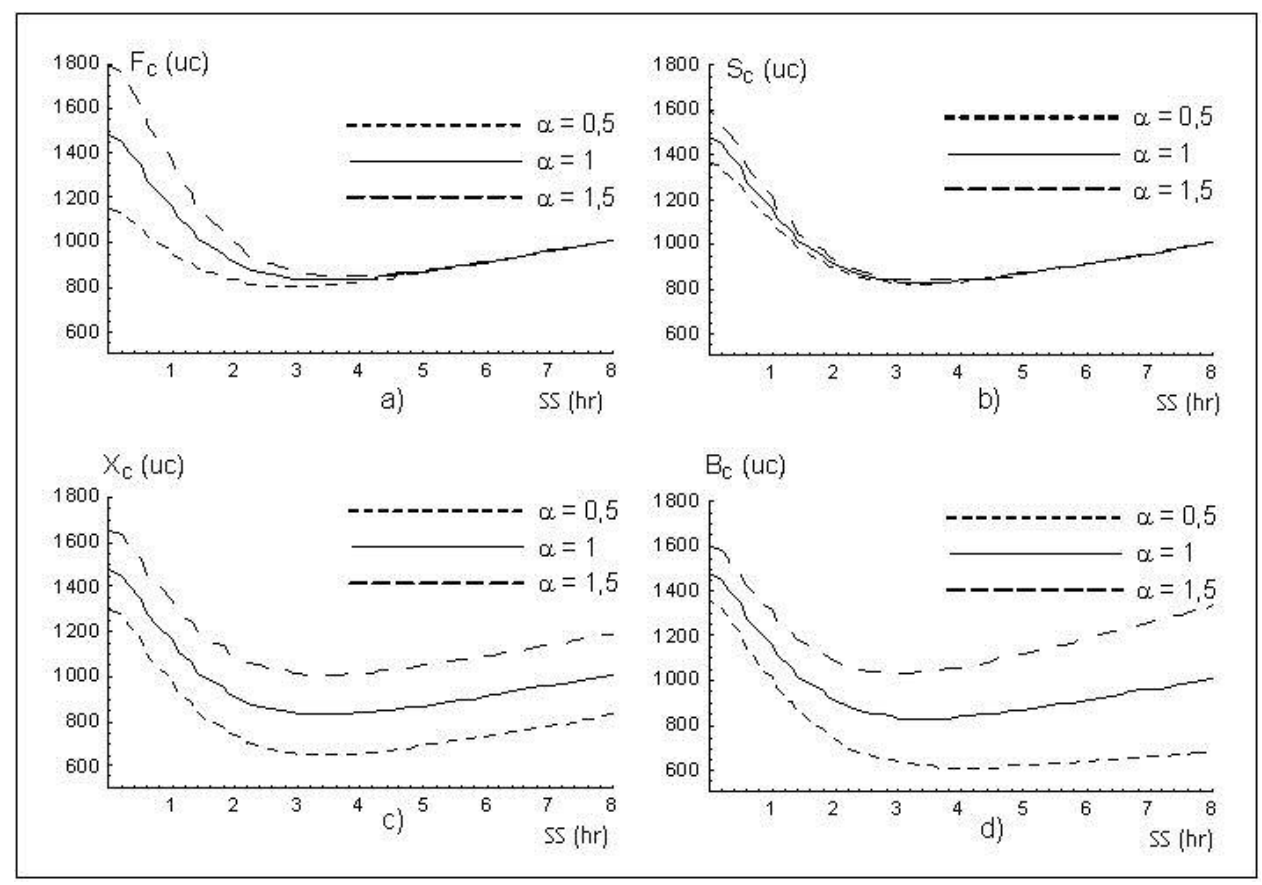

Figure 14 - Cost drivers sensitivity analysis 


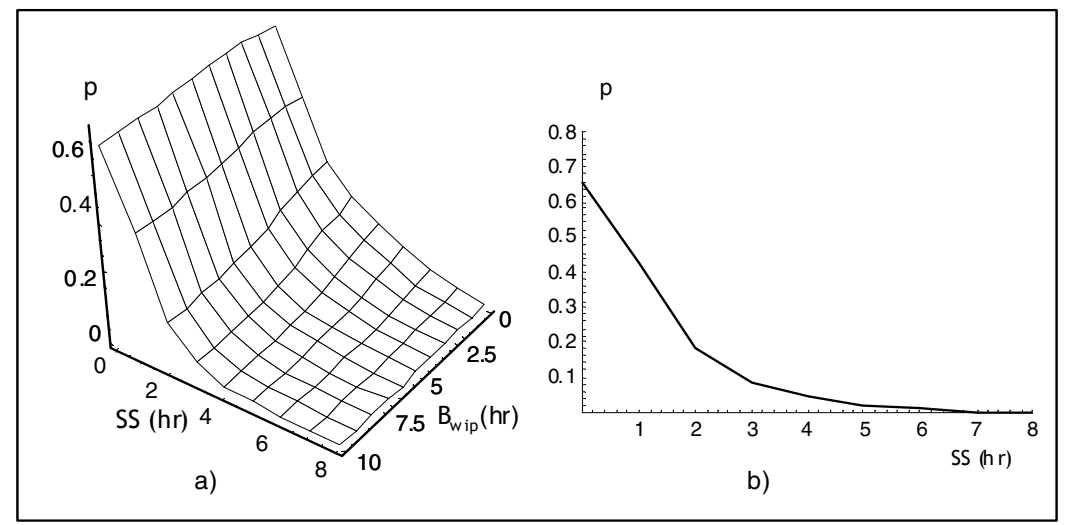

Figure 15 - Daily probability of failure 


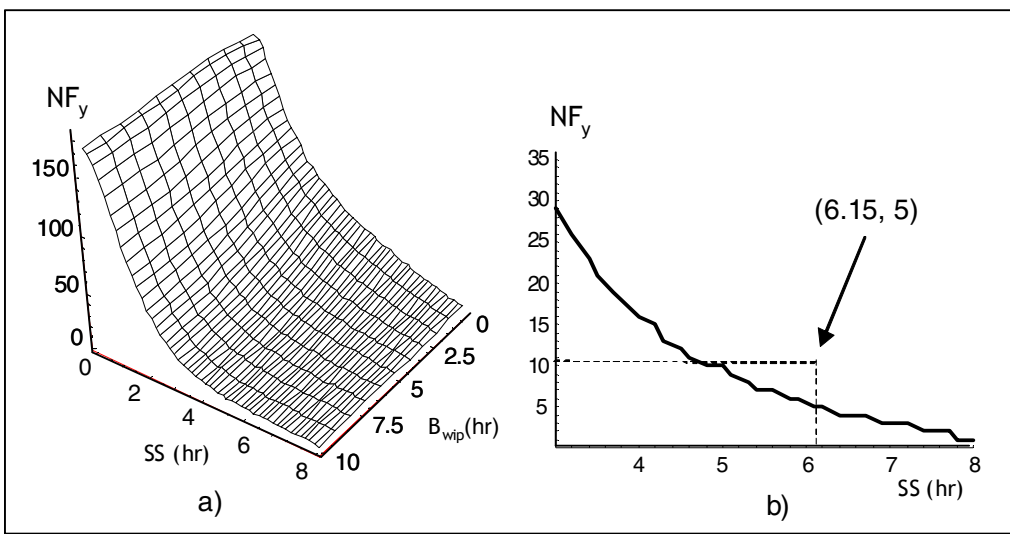

Figure 16 - Expected number of failures per year 


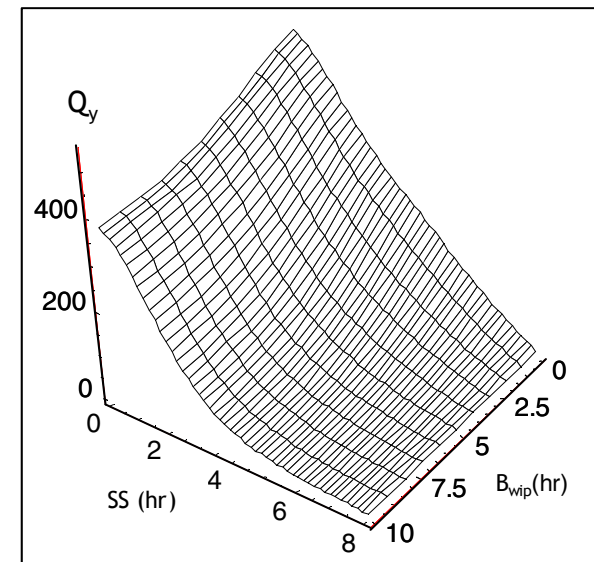

a)

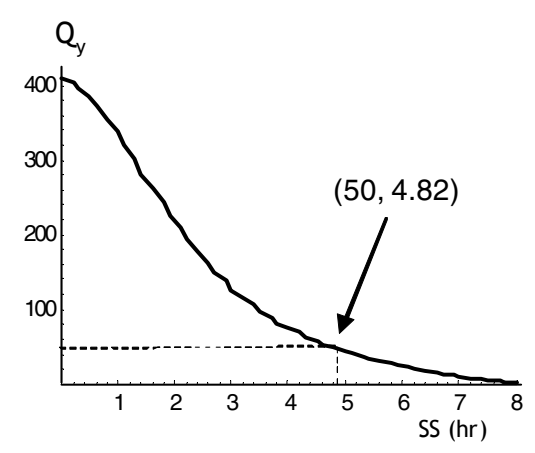

b)

Figure 17 - Expected quantity not delivered per year 


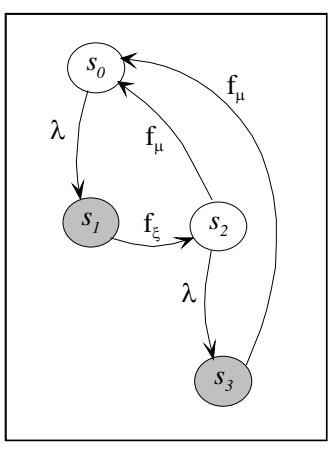

Figure A1 - Internal model of a redundant cell 


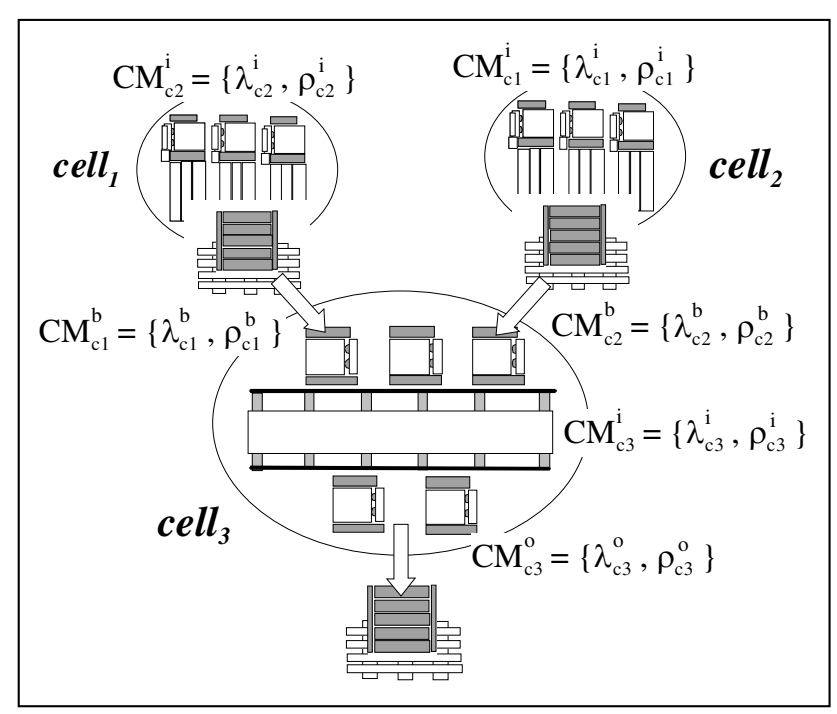

Figure A2 - Multi-cell canonical model 


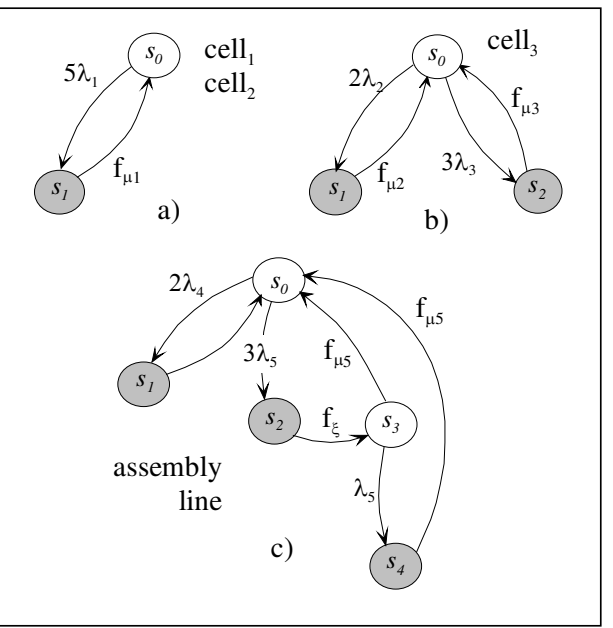

Figure A3 - PartsSupplier internal models 
Table A1 - Density functions

\begin{tabular}{|c|c|}
\hline Cell $_{1}$ and $\mathrm{Cell}_{2}$ & \\
\hline $\mathrm{f}_{\lambda_{1}}(\mathrm{t})=\lambda_{1} \mathrm{e}^{-\lambda_{1} \mathrm{t}} \quad \mathrm{f}_{\mu_{1}}(\mathrm{t})=4 \mu_{1}^{2} \mathrm{te}^{-2 \mu_{1} \mathrm{t}}$ & $\lambda_{1}=0,005 \mathrm{~h}^{-1}, \mu_{1}=1 \mathrm{~h}^{-1}$ \\
\hline \multicolumn{2}{|l|}{$\mathrm{Cell}_{3}$} \\
\hline $\begin{array}{l}\mathrm{f}_{\lambda_{2}}(\mathrm{t})=\lambda_{2} \mathrm{e}^{-\lambda_{2} \mathrm{t}} \\
\mathrm{f}_{\mu_{2}}(\mathrm{t})=27 \mu_{2}{ }^{3} \mathrm{t}^{2} \mathrm{e}^{-3 \mu_{2} \mathrm{t}} / 2\end{array}$ & $\lambda_{2}=0,005 \mathrm{~h}^{-1}, \mu_{2}=0,2 \mathrm{~h}^{-1}$ \\
\hline $\mathrm{f}_{\lambda_{3}}(\mathrm{t})=\lambda_{3} \mathrm{e}^{-\lambda_{3} \mathrm{t}} \quad \mathrm{f}_{\mu_{1}}(\mathrm{t})=\mu_{3} \mathrm{e}^{-\mu_{3} \mathrm{t}}$ & $\lambda_{3}=0,005 \mathrm{~h}^{-1}, \mu_{3}=1 \mathrm{~h}^{-1}$ \\
\hline \multicolumn{2}{|l|}{ Wip buffer } \\
\hline $\mathrm{f}_{\mathrm{b}}(\mathrm{t})=\frac{27 \mu_{\mathrm{b}}{ }^{3} \mathrm{t}^{2} \mathrm{e}^{-3 \mu_{\mathrm{b}} \mathrm{t}}}{2}$ & $\mu_{b}=0,5 \mathrm{~h}^{-1}$ \\
\hline \multicolumn{2}{|l|}{ Assembly line } \\
\hline $\begin{array}{l}\mathrm{f}_{\lambda_{4}}(\mathrm{t})=\lambda_{4} \mathrm{e}^{-\lambda_{4} \mathrm{t}} \\
\mathrm{f}_{\mu_{4}}(\mathrm{t})=27 \mu_{4}{ }^{3} \mathrm{t}^{2} \mathrm{e}^{-3 \mu_{4} \mathrm{t}} / 2\end{array}$ & $\begin{array}{l}\lambda_{4}=0,005 \mathrm{~h}^{-1}, \mu_{4}=1 / 6 \mathrm{~h}^{-1} \\
\lambda_{5}=0,005 \mathrm{~h}^{-1}, \mu_{5}=2 \mathrm{~h}^{-1}\end{array}$ \\
\hline
\end{tabular}


Table A2 - Cost drivers

\begin{tabular}{lc}
\hline$\alpha_{X}$ & 1 \\
\hline$\alpha_{S S}$ & 0.2 \\
\hline$\alpha_{\text {Bwip }}$ & 0.1 \\
\hline$\alpha_{S}$ & 1 \\
\hline$\alpha_{P}$ & 4 \\
\hline
\end{tabular}

